\title{
Experimental determination of intragranular helium diffusion rates in boron carbide $\left(B_{4} C\right)$
}

\author{
Denis Horlait ${ }^{\mathrm{a},}{ }^{*}$, Dominique Gosset $^{\mathrm{b}}$, Aurélien Jankowiak ${ }^{\mathrm{b}}$, Vianney Motte ${ }^{\mathrm{b}}$, Nicolas Lochet ${ }^{\mathrm{b}}$, \\ Thierry Sauvage ${ }^{c}$, Eric Gilabert ${ }^{\mathrm{a}}$ \\ ${ }^{a}$ CNRS/IN2P3 and University of Bordeaux, Centre d'Etudes Nucléaires de Bordeaux-Gradignan, UMR 5797, \\ Chemin du Solarium, 33175 Gradignan, France \\ ${ }^{b}$ DEN-Service de Recherches Métallurgiques Appliquées, CEA, Université Paris-Saclay, F-91191, Gif-sur- \\ Yvette, France \\ ${ }^{c}$ CEMHTI, CNRS UPR3079, Université d'Orléans, F-45071 Orléans Cédex 2, France \\ *Corresponding Author: horlait@.cenbg.in2p3.fr
}

\begin{abstract}
Boron carbide, $\mathrm{B}_{4} \mathrm{C}$, is widely used as a neutron absorber in nuclear reactors. Since neutron absorption by ${ }^{10} \mathrm{~B}$ leads to ${ }^{4} \mathrm{He}$ production, it appears necessary to study $\mathrm{He}$ behavior and its possible effects on the $\mathrm{B}_{4} \mathrm{C}$ ceramic. In this study, the diffusion characteristics of ion-implanted $\mathrm{He}$ in $\mathrm{B}_{4} \mathrm{C}(500$ $\mathrm{keV}$, fluences from $1 \times 10^{+13}$ to $2 \times 10^{+15} \mathrm{He} \mathrm{cm}^{-2}$ ) were investigated mainly by Thermo-Desorption Spectroscopy (TDS) from $600^{\circ} \mathrm{C}$ up to $\mathrm{B}_{4} \mathrm{C}$ melting point. The experiments were done on dense $\mathrm{B}_{4} \mathrm{C}$ samples having large grains $(30-60 \mu \mathrm{m})$ to render grain boundaries effects on He outward diffusion ineffective and thus to access intragranular He diffusion kinetics. From controlled temperature ramp experiments, it was notably observed that He release was realized in two main stages. A first $\mathrm{He}$ population was able to exit the material at moderate temperatures by interstitial diffusion. Then a second population was quantitatively released only over $1150^{\circ} \mathrm{C}$. This was attributed to He atoms that, in their initial interstitial diffusion course at moderate temperatures from their implantation sites, got trapped in defect aggregates and/or He bubbles. As the nucleations of both these traps are expected to be related to helium and irradiation defect concentrations, the ratio of the two He populations was indeed found to be correlated with the implantation fluence. From the obtained He release curves, the apparent activation energies $\left(\mathrm{E}_{\mathrm{a}}\right)$ of $\mathrm{He}$ intragranular diffusion in $\mathrm{B}_{4} \mathrm{C}$ was determined $(2.6-3.1 \mathrm{eV})$ in the $800-1100^{\circ} \mathrm{C}$ temperature range. This value appears slightly higher than the one determined at lower temperatures, hinting that a change in diffusion mechanism may occur around $800^{\circ} \mathrm{C}$. The apparent $\mathrm{E}_{\mathrm{a}}$ of $\mathrm{He}$ detrapping from He bubbles $(\sim 2.5 \mathrm{eV})$ and from defect aggregates $(\sim 4 \mathrm{eV})$ were also determined for temperatures within $1200-1500^{\circ} \mathrm{C}$.
\end{abstract}

KEYWORDS: Boron carbide - Helium - Diffusion - Activation Energy - Neutron Absorber

\section{HIGHLIGHTS}

- Diffusion of helium implanted in $\mathrm{B}_{4} \mathrm{C}$ was studied from $600^{\circ} \mathrm{C}$ to $\mathrm{B}_{4} \mathrm{C}$ melting point

- Helium can be efficiently trapped in bubbles or in defect aggregates up to $\sim 1150^{\circ} \mathrm{C}$

- Apparent $\mathrm{E}_{\mathrm{a}}$ of $\mathrm{He}$ interstitial diffusion $\left(800-1100^{\circ} \mathrm{C}\right)$ in $\mathrm{B}_{4} \mathrm{C}$ determined: $2.6-3.1 \mathrm{eV}$

- Apparent $\mathrm{E}_{\mathrm{a}}$ of He detrapping from bubbles: $\sim 2.5 \mathrm{eV}$; from defect aggregates: $\sim 4.0 \mathrm{eV}$ 


\section{INTRODUCTION}

Boron carbide, $\mathrm{B}_{4} \mathrm{C}$, is commonly used in nuclear cores as a neutron absorber, owing to the high neutron cross section of ${ }^{10} \mathrm{~B}$ and other favourable characteristics such as a high melting point $\left(\sim 2450^{\circ} \mathrm{C}\right)$, irradiation resistance, decades of industrial experience, etc. ${ }^{1}$. Moreover its characteristics make it a serious candidate for neutron absorption application in future Gen-IV reactors ${ }^{2}$. When submitted to a neutron flux, ${ }^{10} \mathrm{~B}$ atom mostly undergoes the $(\mathrm{n}, \alpha)$ absorption reaction leading to the formation of ${ }^{7} \mathrm{Li}$ and ${ }^{4} \mathrm{He}$. As a consequence, in fast neutron reactors, a spent $\mathrm{B}_{4} \mathrm{C}$ would accumulate up to $\sim 10 \mathrm{~mol} . \%$ of $\mathrm{He}^{3}$. Experimentally, aggregation of $\mathrm{He}$ in the form of intra- and/or intergranular bubbles is commonly reported above $500^{\circ} \mathrm{C}$, inducing anisotropic grain swelling and microcracking at both grain and grain boundaries scale. ${ }^{4-7}$ As recently reminded by Motte et al. ${ }^{8}$, knowledge of the diffusion mechanisms and kinetics of $\mathrm{He}$ in $\mathrm{B}_{4} \mathrm{C}$ is still scarce, even though considerable works were made ${ }^{8-17}$ because of the numerous parameters to account for (reactor irradiated $\mathrm{B}_{4} \mathrm{C}$ vs. He implanted $\mathrm{B}_{4} \mathrm{C}$ vs. numerical simulations, $\mathrm{B}_{4} \mathrm{C}$ microstructure, He concentration and so on). To this aim an experimental study on the He diffusion in $\mathrm{B}_{4} \mathrm{C}$ was carried out in simplified conditions, i.e. ${ }^{4} \mathrm{He}$ was implanted in $\mathrm{B}_{4} \mathrm{C}$ at a low concentration in order to minimize structural defect and bubbles formations. In addition, large grains size $\mathrm{B}_{4} \mathrm{C}$ sample were used to render grain boundaries influence marginal. This study appears very complementary to previous works on He diffusion in $\mathrm{B}_{4} \mathrm{C}^{8-17}$, since it was possible to cover unexplored temperatures domain $\left(600^{\circ} \mathrm{C}\right.$ up to $\mathrm{B}_{4} \mathrm{C}$ melting point) and to investigate kinetics of He release from traps from $\sim 1200^{\circ} \mathrm{C}$.

\section{EXPERIMENTAL}

Sample preparation. Boron carbide samples were prepared from a high density, large grain size pellet (diameter $20 \mathrm{~mm}$, height $20 \mathrm{~mm}$ ). Starting powder was a commercially available high purity powder $^{18}$ (European Reference Materials, ERM ED102) supplied by BAM (Bundesanstalt für Materialforschung und Prüfung, Berlin). The samples were sintered into a $20 \mathrm{~mm}$ diameter graphite die using a Dr. Sinter SPS-8.4MK-VIII (Fuji Electronics Industrial Co. Ltd., Japan) under a uniaxial pressure of $40 \mathrm{MPa}$ and $2200^{\circ} \mathrm{C}$. A dwell time of $2 \mathrm{~min}$ and a heating rate of $200^{\circ} \mathrm{C} \cdot \mathrm{min}^{-1}$ were applied. Density of sintered samples was determined by Archimedes' method in water leading to a minimum value of $98 \%$ of TD (Theoretical Density). The pellet was then sliced and each obtained disc was mirror-polished to improve EBSD (Electron BackScatter Diffraction) observations and diffusion rates measurements accuracy. In order not to disrupt helium diffusion toward the surface, a $3 \mathrm{~h}$ thermal treatment at $1600^{\circ} \mathrm{C}$ under vacuum in a graphite furnace was performed allowing healing the surface polishing defects.

EBSD observations show the materiel is isotropic, with no noticeable preferred orientation. According to Figure 1a, the grain size distribution was found in the range $30-60 \mu \mathrm{m}$ (Figure 1) therefore helium trapping by the grain boundaries can then be neglected ${ }^{19}$. The twin density as observed by TEM is low (in fact, no twin occurrence in the few observed samples, about $10 \times 2 \mu \mathrm{m}^{2}$ large): this is an important point since twin boundaries are known as helium trapping sites. EBSD observations show the materiel is isotropic, with no noticeable preferred orientation. 

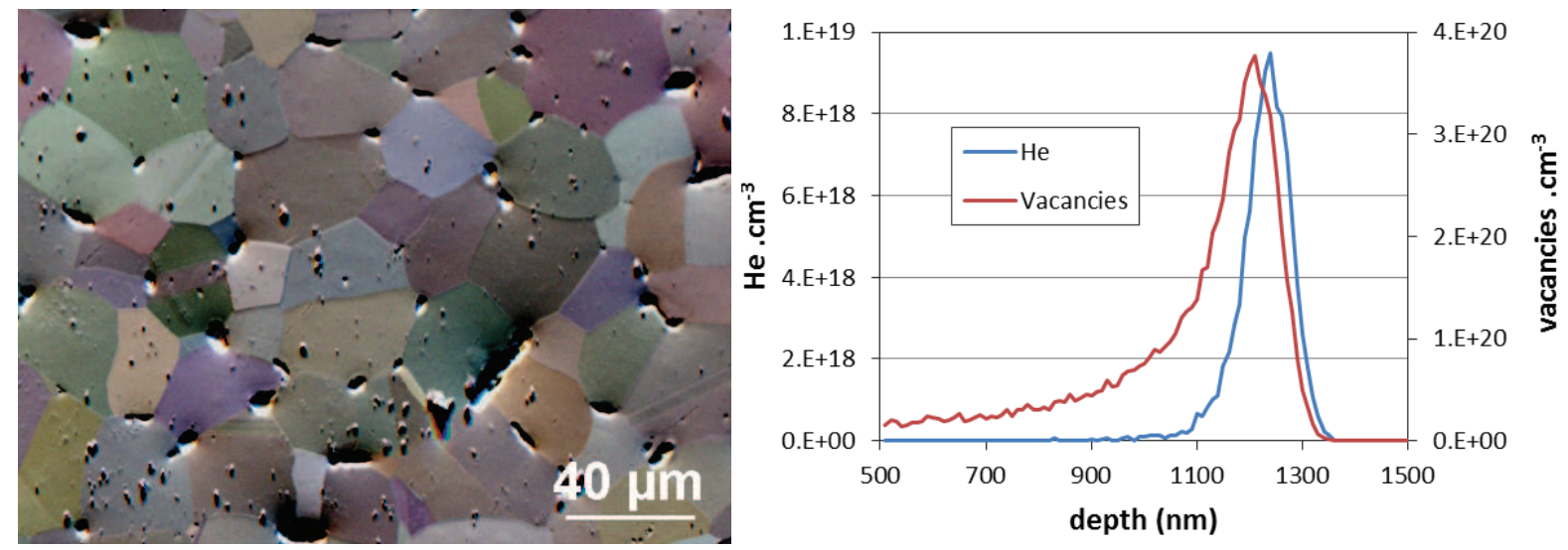

Figure 1. Microstructure of the material and TRIM calculation for the implantation of $500 \mathrm{keV}$ (incidence $15^{\circ}$ ) ${ }^{4} \mathrm{He}$ in $\mathrm{B}_{4} \mathrm{C}$ (here for $1 \times 10^{+14} \mathrm{He} / \mathrm{cm}^{2}$ ).

Helium-4 implantation was performed on the Jannus-Saclay facility ${ }^{20,21}$.at room temperature with an ion energy of $500 \mathrm{keV}$ and with a flux of $10^{12}$ at. $\mathrm{cm}^{2} . \mathrm{s}^{-1}$ thus limiting sample overheating. Three different fluences were selected, $1 \times 10^{+13}, 1 \times 10^{+14}$ and $1 \times 10^{+15}$ at.cm ${ }^{-2}$ which corresponds respectively to helium concentrations at the implantation peak ranges from $7.10^{-4}$ to $7.10^{-2}$ mol.\%. From the results of Motte et al. ${ }^{19}$, this leads either to isolated atoms or the formation of clusters when heating above $600{ }^{\circ} \mathrm{C}$. The He implantation profiles were calculated using SRIM 201322. The range is $1.22 \mu \mathrm{m}$ and the straggling $62 \mathrm{~nm}$ taking into account a beam incidence angle of $15^{\circ}$. From Figure $1 \mathrm{~b}$, it is worth noting that the damage peak is close the implantation one, therefore each $\mathrm{He}$ atom is surrounded by up to 40 point defects (Figure 1).

The three samples used for plateau measurements were afterwards heated up to their fusion in the TDS (Thermo-Desorption Spectroscopy, described hereafter) facility so that the implanted He content could be accurately determined. Implanted helium dose of $1.05 \times 10^{+13}, 1.08 \times 10^{+14}$ and $1.08 \times 10^{+15} \mathrm{at.cm}^{-2}$ were respectively found, in good agreement with the targeted doses.

Thermo-Desorption Spectroscopy (TDS). Measurement of helium release from the $\mathrm{B}_{4} \mathrm{C}$ samples as a function of time and temperature were performed at CENBG on the PIAGARA platform (Interdisciplinary Platform for Noble Gas Analysis), which is dedicated to rare gases down to ultratrace levels quantification by mass spectrometry. ${ }^{23-26}$ The experimental device is made of interconnected distinct volumes, comprising (1) the heating chamber, (2) several purification devices, (3) a calibration setup and a mass spectrometer (Micromass 12 by VG, in-house modified to perform specifically rare gases measurements). The whole setup is supplemented by a set of pumping units, which guarantees ultra-high vacuum conditions (in the $1.10^{-6}$ to $1.10^{-7} \mathrm{~Pa}$ range).

The heating chamber consists in a high-vacuum cell of cylindrical shape $(10 \mathrm{~cm}$ inner diameter / 20 $\mathrm{cm}$ height) sealed on top by a flange supporting a Kodial glass window. To evacuate the generated heat and avoid walls overheating, the sides of the heating chamber are cooled down by an external circulation of water. Samples are $\sim 0.15 \mathrm{~cm}^{2}$ platelets like specimen with the implanted side facing up onto a molybdenum sample holder designed to increase temperature homogeneity across the sample surface. This Mo sample holder is itself placed onto a $4 \mathrm{~cm}$ height tungsten cylinder in order to keep the sample away from the uncooled down flange of the heating chamber.

For this study, a high power laser beam was used as heating technique. Indeed, previous studies most notably on nuclear materials ${ }^{23,24,27-29}$ were often limited by the maximum temperature achievable by 
conventional heating $\left(\sim 1400^{\circ} \mathrm{C}\right)$. A laser heating further offers the possibility to achieve ultra-high heating rates and allows accurate local heating to high-temperature of the sample. The laser device is a LuOcean M2, Lumics GmbH, Berlin, Germany, delivering a 0 to $650 \mathrm{~W}$ continuous wave $933 \mathrm{~nm}$ laser beam. It also integrates a $1 \mathrm{~mW} 632 \mathrm{~nm}$ laser for beam alignment. The laser beam is brought to the sample and Mo sample holder through an optical fibre. The size of the beam when touching the sample (and its holder) is adapted by the position of a converging lens; in this study we adjusted it to have a diameter about twice that of the sample, ensuring optimal temperature homogeneity. On its course between the optical fibre and the sample, the beam also passes through a round homogenizer lens provided by HOLO/OR Ltd. (Rehovot, Israel): this device transforms the Gaussian type power profile of the laser beam into a so-called "top-hat" profile, therefore increasing the temperature homogeneity across the heated sample. To monitor the heating, a camera is placed over the heating chamber. A pyrometer (Metis M322 with a $600-2300^{\circ} \mathrm{C}$ measurement range, produced by Sensortherm $\mathrm{GmbH}$, Sulzbach, Germany) is also employed to measure the temperature of the $\mathrm{B}_{4} \mathrm{C}$ samples during the experiments. It is a 2-colors pyrometer analysing the 1.65-1.8 $\mu \mathrm{m}\left(\lambda_{1}\right)$ and 1.45-1.65 $\mu \mathrm{m}\left(\lambda_{2}\right)$ ranges. The spot size is approximately $1 \mathrm{~mm}^{2}$. An edgepass lens cutting off wavelength below $1.2 \mu \mathrm{m}$ is placed just in front of the pyrometer integrated optics to protect it against the intense light emitted at lower wavelengths. For the $\mathrm{B}_{4} \mathrm{C}$ samples experiments an emissivity $\varepsilon$ of 0.85 was selected based on the few experimental values found in the literature ${ }^{30-34} . \mathrm{B}_{4} \mathrm{C}$ is reported as being nearly a "grey body" resulting in a low variation of its emissivity with both temperature and wavelength. This was indirectly verified by the evolution of $\lambda_{2} / \lambda_{1}$ ratio varying from 0.985 to 1.03 amongst all experiments on $\mathrm{B}_{4} \mathrm{C}$ leading to a maximum shift only $3 \%$ between $\varepsilon_{1}(1.65-1.8 \mu \mathrm{m})$ and $\varepsilon_{2}(1.45-1.65 \mu \mathrm{m})$. An in-house Labview program was developed to remotely control the heating. Based on pyrometer readings and PID control from Siemens automat Simatic s7-1200, temperatures are monitored at better than $0.2^{\circ} \mathrm{C}$ during plateaux and less than $2^{\circ} \mathrm{C}$ in ramps.

In the experiments up to $\sim 1850^{\circ} \mathrm{C}$, the heating chamber was directly opened to the spectrometer with the purification zone in-between. In this "open" configuration the gases evolved from the samples (and incidentally from the surrounding heated components) were treated "in-flight" by purification devices consisting in high specific surface charcoals at liquid nitrogen temperature, SORB-AC traps (SAES Getter, Lainate, Italy) and $\mathrm{Ti}$ sponges. These devices aim to remove most of the unwanted gas that could impair the continuous mass spectrometry measurements (basically all gaseous species except $\mathrm{He}$ ). For high temperatures, the quantities of evolved gases were too high and the in-flight purification in the open configuration was not sufficient to not disrupt the spectrometric measurements. In the latter case, a sampling configuration was adopted, i.e. a fraction of the gases evolved over a known period of time is relaxed in the purification zone for a minimum of 4 min then a fraction of this purified gas is introduced in the spectrometer for analysis. The advantage of the "open" over the "sampling" configuration is the possibility to analyse ${ }^{4} \mathrm{He}$ and ${ }^{3} \mathrm{He}$ every $60 \mathrm{sec}$, while with for "sampling" 20 min are necessary between two measurements.

Before starting the heating of a sample, a tiny amount of a reference ${ }^{3} \mathrm{He}+{ }^{4} \mathrm{He}$ gas is expanded into the working volumes (from the spectrometer to the heating chamber). The experimental isotopic ${ }^{4} \mathrm{He} /{ }^{3} \mathrm{He}$ ratio of the reference gas (close to 0.33 ) was accurately determined by mass spectrometry for few tens of minutes before the start of heating in order to eventually correct the measurements from a natural evolution of the ratio due to micro-leak of the high-vacuum system and/or memory effect of the mass spectrometer. This ratio is very different from that existing in air $\left(1.37 \times 10^{5}\right)$ and in the samples of the present study where the ratio is considered to be zero as only ${ }^{4} \mathrm{He}$ is implanted. As such, and since the introduced reference ${ }^{3} \mathrm{He}$ quantity is precisely known (with a $\pm 6 \%$ confidence), the quantities of the ${ }^{4} \mathrm{He}$ releases from the sample are obtained through the measure of the ${ }^{4} \mathrm{He} /{ }^{3} \mathrm{He}$ ratio ${ }^{23}$. This allows eliminating the great uncertainty related to the spectrometer sensitivity that can greatly 
change from one day and one experimental condition to another. With this setup, we were able to accurately measure effective diffusion rates from $\sim 10^{-17} \mathrm{~m}^{2} \cdot \mathrm{s}^{-1}$. Considering the literature results $\mathrm{s}^{7,8,10}$, this experimentally limited the plateau measurements to temperature greater or equal to $800^{\circ} \mathrm{C}$.

\section{RESULTS}

The fluences actually obtained were measured by melting one coupon of each sample and measuring by mass spectrometry the released He. Doses of $1.05 \times 10^{+13}, 1.08 \times 10^{+14}$ and $1.08 \times 10^{+15}$ at. $\mathrm{cm}^{-2}$ were thereby determined (associated error $\pm 5 \%$ ), quite satisfyingly close to the targeted fluences. These determined fluences were considered as such for data treatment but for simplification we will hereafter continue to name the samples by their initially targeted fluence $\left(1 \times 10^{+13}, 1 \times 10^{+14}\right.$ and $1 \times 10^{+15}$ at. $\left.\mathrm{cm}^{-2}\right)$.

In the present study, a sample of each nominal dose was submitted to a $4^{\circ} \mathrm{C} \cdot \mathrm{min}^{-1}$ heating ramp from $600^{\circ} \mathrm{C}$. The evolution of He release was monitored by mass spectrometry as displayed by Figure 2a. A first release of $\sim 1 \%$ of the He implanted population was always observed below the minimum measurable temperature of our pyrometer $\left(600^{\circ} \mathrm{C}\right)$. These $1 \%$ releases are not represented on Figure 2a but systematically appeared as a small He burst in the middle of the quick ramp from room temperature to $600^{\circ} \mathrm{C}$. Such minor release was also observed by Kovyrshin ${ }^{13}$ around $150^{\circ} \mathrm{C}$. The origin of this phenomenon remains unclear but it could be related to He implanted very close to open porosity and/or to a contribution of the samples sides that are damaged by the cutting. After this initial minor burst, two main release stages were observed for all three implanted doses. This is well evidenced in Figure $2 b$ by derivating the cumulated He released fraction against temperature. For the first release peak, the maximum release rate is found at $\sim 900^{\circ} \mathrm{C}$ for the $1 \times 10^{+15}$ sample and this maximum temperature shifts up to $\sim 980^{\circ} \mathrm{C}$ for the $1 \times 10^{+13}$ sample.

Such observation, i.e. the temperature of maximum release rate increasing with decreasing implanted dose, was also found during preliminary tests on $2 \times 10^{+15}$ and $2 \times 10^{+12} \mathrm{He}^{-\mathrm{cm}^{-2}}$ samples $^{9}$. Conversely for the second peak the $1 \times 10^{+13}$ sample reaches a maximum release rate at $\sim 1400^{\circ} \mathrm{C}$ while that of $1 \times 10^{+15}$ sample is obtained at $\sim 1750^{\circ} \mathrm{C}$. It is clear that at least two distinct $\mathrm{He}$ populations are being released, one quasi-exclusively in the $700-1150^{\circ} \mathrm{C}$ range, and the other quantitatively from over $1200^{\circ} \mathrm{C}$. Based on the characterisation made on very similar samples ${ }^{8,9}$, but also as confirmed by the diffusion models we had to apply to accurately model the releases (presented in the next Section), it is safe to consider that the first release stage concerns only isolated He atoms. These He atoms have diffused out by interstitial diffusion ${ }^{14-16}$ while avoiding in their path to aggregate with other He atoms to nucleate a defect aggregate or a bubble and while avoiding to be trapped in such trap. As detailed later, the second release stage then concerns the release of He atoms that have been trapped. As the two main He releases are fairly well separated, the fractions of "interstitial" $\mathrm{He}$ and of "trapped" He can be easily graphically estimated. The fitted curves presented in the next section determined interstitial He to be $76 \%, 57.5 \%$ and $37.5 \%$ of the total He population (with a $\pm 1 \%$ confidence) for the $1 \times 10^{+13}, 1 \times 10^{+14}$ and $1 \times 10^{+15}$ samples, respectively. During preliminary works on similar samples, fractions of He released through interstitial migration (untrapped) were found to respectively $\sim 80 \%$ and $26 \%$ in $2.10^{+12}$ and $2.10^{+15} \mathrm{He}^{-\mathrm{cm}^{-2}}$ samples ${ }^{9}$, agreeing well with the trend evidenced here. Such observation is also in agreement with the intuitive fact, experimentally confirmed $^{8,9}$, that the more implanted He, the higher the defect concentration along the damage profile (Figure 1b), and the higher the probability to trap a He atom in such defect or to form He aggregates before this He reaches by interstitial diffusion the sample surface. 

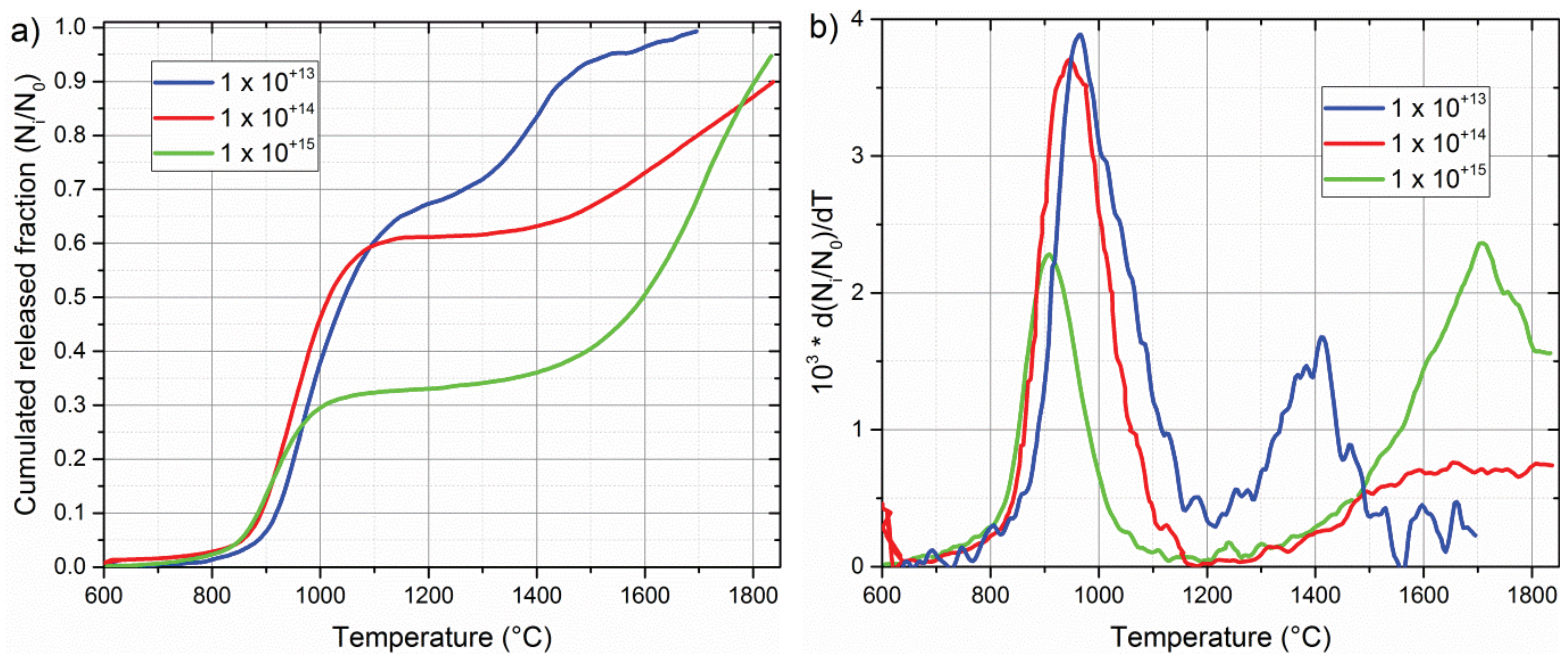

Figure 2. a) Cumulated He released fraction determined by TDS as a function of temperature. Heating ramp of $4^{\circ} \mathrm{C} \cdot \mathrm{min}^{-1} \mathrm{~b}$ ) Derivative as a function of the temperature of the TDS curves.

Following these ramp experiments, successive increasing plateaux heat treatments for another sample of each implantation fluence were realised. The resulting TDS release curves are presented in Figure 3. The general trends observed in the ramp experiments in Figure 2 are found here as well (similar fractions of isolated $\mathrm{He}$, temperature ranges of releases, etc.). In the following section, the two models used to fit the two release stages and extract valuable data such as apparent activation energies of diffusion $\mathrm{E}_{\mathrm{a}}$ are presented. 

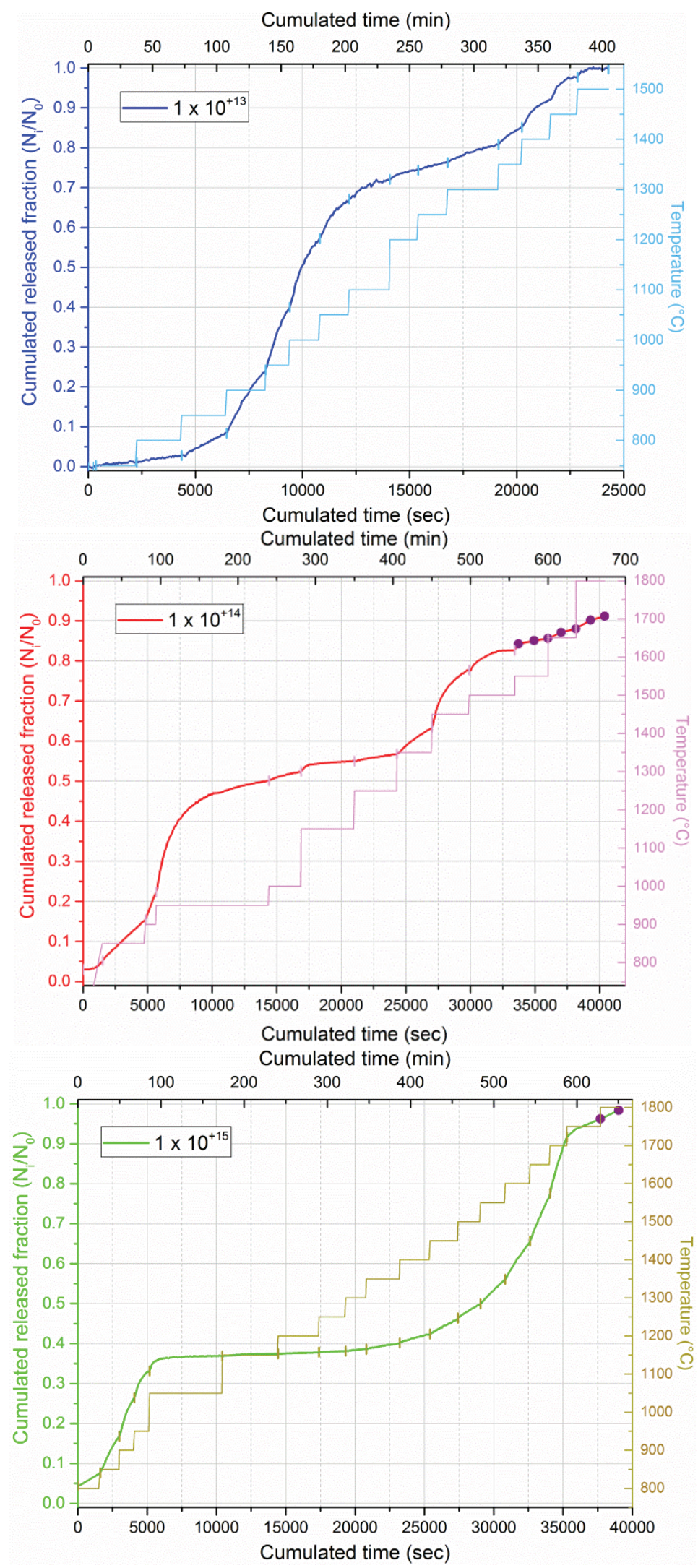

Figure 3. Cumulated He released fraction determined by TDS as a function of time for $1 \times 10^{+13}$, $1 \times 10^{+14}$ and $1 \times 10^{+15}$ at.cm ${ }^{-2}$ samples. The temperature evolution is also plotted (right ordinate axis). The vertical ticks mark temperature changes and the purple dots on the $1 \times 10^{+14}$ and $1 \times 10^{+15}$ curves indicate parts where the "sampling" configuration had to be employed $(\sim 1$ measurement every $20 \mathrm{~min}$ as opposed to 1 per min in the "open" configuration). 


\section{HE RELEASE CURVES MODELLING}

TDS measurements presented in Figure 2 and Figure 3 show the presence of two separate He release peaks indicating at least two different processes that control the helium release process. Based on literature data and on the models that were necessary to efficiently fit the release curves, it can be considered that during annealing, helium can diffuse freely to the surface or become trapped in the defect aggregates or bubbles that are forming meanwhile. At temperatures below $1150^{\circ} \mathrm{C}$, trapped helium remains trapped and as such immobile and only isolated atoms are being released. From $1200^{\circ} \mathrm{C}$, they start to quantitatively exit their traps; considering the mechanism involved in the first stage, it can be assumed that when they exit the traps they diffuse quasi-instantaneously towards the surface (i.e. detrapping is the only limiting process). To process the annealing, a model including two types of He (isolated and trapped) then is proposed. This is based on models related trapping of $\mathrm{He}$ in $\mathrm{UO}_{2}{ }^{35-37}$ Thus the following starting parameters can be defined:

- Cs: isolated (single) He concentration (at. $\left.\mathrm{m}^{-3}\right)$

- $\quad$ b: trapped He concentration, indistinctively in bubbles or in structural defects $\left(\right.$ at. $\left.\mathrm{m}^{-3}\right)$.

- Single He atoms diffuse in $\mathrm{B}_{4} \mathrm{C}$ with a coefficient $D \mathrm{~s}\left(\mathrm{~m}^{2} \cdot \mathrm{s}^{-1}\right)$

- Helium atoms get trapped with an apparent rate $k_{s}\left(\mathrm{~s}^{-1}\right)$ indistinctively of the nature of the trap.

- The trapped He diffuse with the coefficient $D b\left(\mathrm{~m}^{2} \mathrm{~s}^{-1}\right)$.

- Helium atoms can definitively escape traps in the material at the rate $k_{b}\left(\mathrm{~s}^{-1}\right)$

- Coalescence of bubbles and of defects aggregates could be discarded (justification given in few paragraphs).

Considering a one-dimensional diffusion (depth) according to Fick's laws, we can write for each temperature plateau the following coupled system as a function of time $\mathrm{t}$ and depth $\mathrm{x}$.

$$
\left\{\begin{array}{l}
\frac{\partial C s}{\partial t}=D s \frac{\partial^{2} C s}{\partial x^{2}}-k_{s} * C s+k_{b} * C b \\
\frac{\partial C b}{\partial t}=D b \frac{\partial^{2} C b}{\partial x^{2}}+k_{s} * C s-k_{b} * C b
\end{array}\right.
$$

Solving this system can be done at each temperature stage of Figure 3 curves with the constraint that the initial state of $C \mathrm{~s}$ and $\mathrm{Cb}$ for a stage is the final state of the previous stage. The difficulty is that it is almost impossible to correctly determine the 4 free parameters $\left(D \mathrm{~s}, D \mathrm{~b}, k_{s}, k_{b}\right)$ by a least square process. However all the ramp experiments show that there is a clear change around $1100^{\circ} \mathrm{C}-1200^{\circ} \mathrm{C}$ that warrants to make some simplifications of Equations (1) and to split the problem in two parts: low temperature and high temperature.

At low temperature, it can be assumed that the trapping sites are immobile $\left(D_{\mathrm{b}}=0\right)$ and that the trapped He cannot escape $\left(k_{b}=0\right)$ thus allowing to write:

$$
\left\{\begin{array}{c}
\frac{\partial C s}{\partial t}=D s \frac{\partial^{2} C s}{\partial x^{2}}-k_{s} * C s \\
\frac{\partial C b}{\partial t}=k_{s} * C s
\end{array}\right.
$$

To solve this system, the boundary conditions as well as the initial conditions are required. The boundary conditions are zero concentrations at the surfaces at any time:

$$
C \mathrm{~s}(\mathrm{x}=0, \mathrm{t})=C \mathrm{~b}(0, \mathrm{t})=0
$$


For the initial conditions, we assume that implantation produces only free diffusing $\mathrm{He}$ and that trapping occurs only during annealing. Our justification is that despite the fact that $\sim 40$ point defects are expected per implanted He in the implantation zone (Figure 1b), the probability of an He to end up in a structural defect at the end of its implantation course is very low because of our relatively low fluences and thus low trap concentration (for the $1 \times 10^{+15}$ fluence, it can be estimated from Figure $1 \mathrm{a}$ concentration at peak maximum of $4 \%$ defect/atom). As an example, in their study of He diffusion in $\mathrm{UO}_{2}$ with similar He molar concentration but far greater traps concentration, Talip et al. ${ }^{27}$ estimated pre-annealing trapped $\mathrm{He}$ to represent only $5 \%$ of the total He. Furthermore, from the reported $\mathrm{He}$ diffusion coefficients in $\mathrm{B}_{4} \mathrm{C}$ below $800^{\circ} \mathrm{C}^{8-10,12}$, the approximation can be made that no quantitative He trapping occurs during months of storage at room temperature (between the implantations and the TDS experiments) and during the heating ramp up to $800^{\circ} \mathrm{C}$. Therefore the fraction of He initially positioned in a defect should be negligible and as such can be discarded in our modelling.

For the modelling, the initial free He profile is given by TRIM 22 (Figure 1). As such, it can be written the following:

$$
C \mathrm{~s}(\mathrm{x}, \mathrm{t}=0)=C_{\mathrm{TRIM}}(\mathrm{x}) \text { and } C \mathrm{~b}(\mathrm{x}, \mathrm{t}=0)=0
$$

$\mathrm{Cb}$ is defined as trapped gas population supplied during the annealing time by the mobile gas with a trapping frequency $k_{s}$. This is related to the interaction of gas atoms with trapping sites along their migration routes, and is generally described by the following equation:

$$
k_{s}=4 \pi * r_{p} * C_{p} * D s
$$

With $C_{p}(\mathrm{x}, \mathrm{t})$ the concentration of traps at depth $\mathrm{x}$ and time $\mathrm{t}$ and $r_{p}(\mathrm{t})$ the size of the traps. The traps results of the damage queue of the ion implantation so it is legit to approximate $C_{p}(\mathrm{x}, \mathrm{t})$ as:

$$
C_{p}(\mathrm{x}, \mathrm{t})=C_{0}(\mathrm{t}) * \mathrm{dpa}(\mathrm{x})
$$

with $\operatorname{dpa}(\mathrm{x})$ the normalized calculated profile from TRIM of displacement of atoms (Figure 1b) and $\mathrm{C}_{0}(\mathrm{t})$ the concentration of traps at the maximum of the dpa profile (therefore dpa $(\mathrm{x})$ varies from 0 to $1)$.

$r_{p}$ and $C_{0}$ are unknown and their product must be considered as a parameter of the calculation. But a simplification is introduced by considering that the product $r_{p} * C_{0}$ is constant and therefore independent of temperature and time. This simplification is justified because 1) limited changes of such product with annealing temperature are observed for noble gas bubbles in $\mathrm{UO}_{2}{ }^{38,39}$ and 2) because we found that making this couple of parameter vary throughout the heat ramp does not influence the final data of interest ( $E_{a}$ values) more than their determined uncertainty. This simplification thus reduces the number of parameters from $2 * \mathrm{~N}$ ( $\mathrm{N}$ being the number of temperature plateaux) to $\mathrm{N}+1$.

$$
\begin{gathered}
k^{\prime}{ }_{s}=4 \pi * r_{p}(t) C_{0}(t) \\
\left\{\begin{array}{l}
\frac{\partial C s}{\partial t}=D s \frac{\partial^{2} C s}{\partial x^{2}}-k_{s}^{\prime} * d p a(x) * D s * C s \\
\frac{\partial C b}{\partial t}=k_{s}^{\prime} * d p a(x) * D s * C s
\end{array}\right.
\end{gathered}
$$

With $k_{S}^{\prime}$ independent of temperature and time.

The cumulated released fraction $\mathrm{N}_{\mathrm{i}} / \mathrm{N}_{0}$ of $\mathrm{He}$ at the instant $t$ at low temperature then is:

$$
\mathrm{N}_{\mathrm{i}} / \mathrm{N}_{0}(t)=1-\frac{\int_{0}^{\mathrm{e}} C s(\mathrm{x}, \mathrm{t}) \mathrm{dx}+\int_{0}^{\mathrm{e}} C \mathrm{~b}(\mathrm{x}, \mathrm{t}) \mathrm{dx}}{\int_{0}^{\mathrm{e}} C_{\operatorname{TRIM}}(\mathrm{x}) \mathrm{dx}}
$$


With e the sample thickness.

At high temperature, the proposed model is simply a diffusion-free detrapping because diffusion is very fast at these temperatures and is not limiting in any way (e.g. projected interstitial He diffusion coefficient at $1300^{\circ} \mathrm{C}$ should be at minimum $1 \mu \mathrm{m}^{2} \cdot \mathrm{sec}^{-1}$, see Figure 6). We can therefore simplify Equation (1) by stating that $C \mathrm{~s}(\mathrm{x}, \mathrm{t})=0$. A second simplification is to consider the traps as a whole to be immobile up to $1500^{\circ} \mathrm{C}$ at least in the $\mathrm{x}$ direction, i.e. $\mathrm{Db}=0$. This simplification and the temperature limitation are justified by the following:

- Under our high-vacuum conditions $\mathrm{B}_{4} \mathrm{C}$ surface erosion is expected to occur. From the vapour pressure data given by Robson and Gilles ${ }^{40}$, using a vapour pressure calculator ${ }^{41}$ and by considering that the samples never get in equilibrium with their vapour (the latter being quickly trapped in the high vacuum environment by the various traps described in the Experimental section), $\mathrm{B}_{4} \mathrm{C}$ erosion rates as a function of the temperature could be estimated. Indeed, erosion by $\mathrm{B}_{4} \mathrm{C}$ sublimation should start impairing our measurements from $1550^{\circ} \mathrm{C}$ with an average erosion rate of $\sim 1.5 \mathrm{~nm}$. min ${ }^{-1}$ thus $30 \mathrm{~nm}$ of the surface being vaporised during a 20 min plateau (to be compared to the implantation peak depth of $1.22 \mu \mathrm{m}$, Figure $1 \mathrm{~b}$ ). At $1750^{\circ} \mathrm{C}$ for $20 \mathrm{~min}$, the erosion pace should lead to an average erosion depth of $\sim 1 \mu \mathrm{m}$, i.e. close to the He implantation depth, possibly explaining the maximum release rate for the $1 \times 10^{+15}$ sample at this temperature (Figure $2 \mathrm{~b}$ ). One can argue that when the erosion front reaches the bubbles located $1.22 \mu \mathrm{m}$ below the initial surface, it should provoke a quasi-instantaneous massive release of $\mathrm{He}$, which is not experimentally observed. However, it should be reminded that erosion rates generally depends on the crystallographic orientation of each grain ${ }^{42,43}$ and as the studied material is not textured, it should prevent such burst release. Nonetheless surface erosion being a process exponentially dependant on temperature, this presumably explains the apparent doubleexponential increase of release rates for the $1 \times 10^{+15}$ sample in Figure 7. Unfortunately, this also means that the diffusion coefficients obtained from $1550^{\circ} \mathrm{C}$ are greatly influenced by $\mathrm{B}_{4} \mathrm{C}$ vaporization (and by bubble migration) resulting in data acquired from $1550^{\circ} \mathrm{C}$ being no longer exploitable (except for the determination of the total amount of implanted $\mathrm{He}$ ).

- Tarasikov ${ }^{44}$ investigated by TEM the evolution of $\mathrm{He}$ bubbles in $\mathrm{B}_{4} \mathrm{C}$ after tens of hours of annealings. It was observed that after annealing $60 \mathrm{~h}$ at $1400^{\circ} \mathrm{C}$, the intragranular bubbles shapes evolved but not their volume suggesting no bubble merging and consequently no bubble diffusion in the material. Conversely, after $10 \mathrm{~h}$ at $1600^{\circ} \mathrm{C}$, bubble diffusion is evidenced. By limiting our model application to $1500^{\circ} \mathrm{C}$, we can confidently consider that after few tens minutes below $1500^{\circ} \mathrm{C}$, diffusion of bubble is inactive.

Based on this, the evolution of $\mathrm{He}$ concentration in traps in the $1200^{\circ} \mathrm{C}-1500^{\circ} \mathrm{C}$ range therefore follows Equation 5:

$$
\frac{\partial C b(t)}{\partial t}=-k_{b} * C b(t)
$$

Calculations were made using the FlexPDE software (PDE Solutions, Inc.), which allows differential equations to be solved by finite element analysis. An application of the models is shown in Figure 4 for the $1 \times 10^{+13}$ sample as an example. To determine the error associated to the final data of interest (apparent activation energy $E_{a}$ for both models, pre-exponential factor $D_{0}$ and frequency factor A respectively for the low- and high-temperature models), we applied the low-temperature model for the experiments of Figure 3 with several fixed $k_{s}$ values varying around their predetermined optimal 
values and looked at the goodness of fits. It was found that only narrow ranges of $k_{s}$ values allow a satisfying reproduction of the experimental data. Using these narrow ranges of satisfying $k_{s}$ values allowed determining the corresponding uncertainty ranges for $\mathrm{E}_{\mathrm{a}}$ (around $\pm 10 \%$ ) and for $\mathrm{D}_{0}( \pm 1$ order of magnitude) for the three fluences as reported in Table 1 and Table 2. The quite large error for $\mathrm{D}_{0}$ is due to the fact that it is determined by an interpolation at 0 abscissa by an exponential function from data points ranging $7.2<10000 / \mathrm{T}<8.9$.

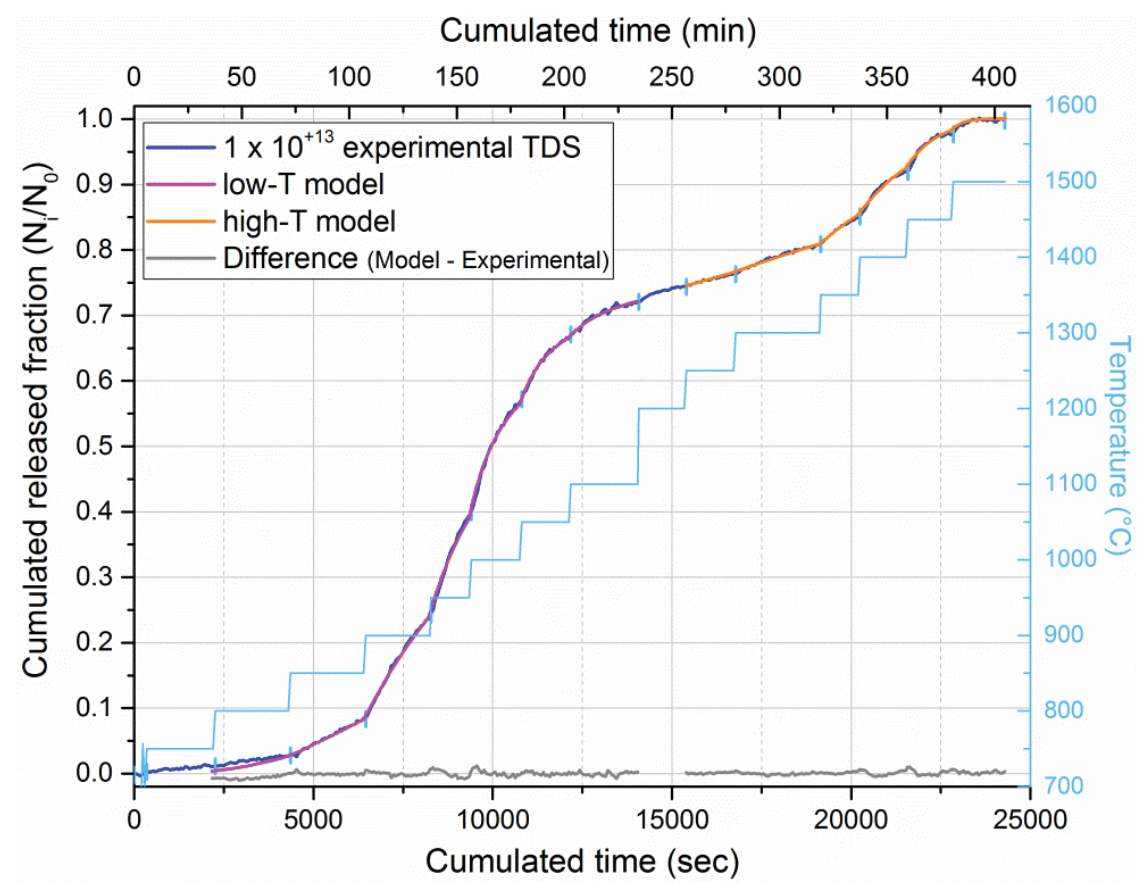

Figure 4. Example ( $1 \times 10^{+13} \mathrm{at}_{\mathrm{cm}}^{-2}$ sample) of the application of the fit models used to extract $D \mathrm{~s}$ and $k_{b}$ values reported in Figure 6 and Figure 7, respectively. For details about the fit models, the reader should refer to the main text.

On Figure 4, there are therefore seven isotherms (every $50^{\circ} \mathrm{C}$ in the $750-1100^{\circ} \mathrm{C}$ range) which were successfully fitted with the model considering isolated $\mathrm{He}$ release by interstitial diffusion in competition with He trapping. Diffusion coefficients were obtained and reported in Figure 6. Amongst the plateaux performed, the $1200^{\circ} \mathrm{C}$ isotherm cannot be fitted either with the model applied for low temperatures or with the model applied for higher temperatures. It can be deduced from this point that the first interstitial population of $\mathrm{He}$ has therefore mainly left and that at $1200^{\circ} \mathrm{C}$ the low He release is a combination of a few remaining interstitial $\mathrm{He}$ and of the very first measurable release of the second trapped population of He. In Figure 4, for the second release peak (Figure 4), the isotherm at $1250^{\circ} \mathrm{C}$ shows that there is no delay between the start of the plateau and the start of the He release (in other words, the rate of He release is immediately set as soon as the plateau temperature is reached on the contrary to e.g. the $850^{\circ} \mathrm{C}$ plateau in Figure 4). This is in agreement with the detrapping mechanism that we postulate: detrapped He reached the surface quasi-instantaneously and He release is only limited by detrapping rate. Application of such model allowed to perfectly fit the release curve in the $1250-1500^{\circ} \mathrm{C}$ range: the difference between experimental and fitting curves is below the level of background noise as shown by the difference plot in Figure 4 (in grey).

In order to further validate the fitting models used, the determined $\mathrm{D}_{0}, \mathrm{~A}$ and $\mathrm{E}_{\mathrm{a}}$ values were applied to the ramp experiments to see if we could reproduce (and thus anticipate) the ramp release curves. A representative example is given in Figure 5 for the $1 \times 10^{+15}$ sample fluence and a $4^{\circ} \mathrm{C} \cdot \mathrm{min}^{-1} \mathrm{ramp}$. As 
discussed previously, $\mathrm{E}_{\mathrm{a}}$ values determination exhibits an error of $\pm 10 \%$, therefore this error margin was taking into account in Figure 5 to simulate release curves. It is demonstrated that using the presented model and the results of the plateau experiment it is possible to reproduce the experimental curve of the $4^{\circ} \mathrm{C} \cdot \mathrm{min}^{-1} \mathrm{ramp}$ from $\sim 900^{\circ} \mathrm{C}$ within the determined range of uncertainty for $\mathrm{E}_{\mathrm{a}}$. If the heating rates do not significantly influence He release behaviour, it is then possible to anticipate the release curves of our samples. The main disagreement between simulated and experimental curves occurs below $800^{\circ} \mathrm{C}$ for all three fluences and suggests the underestimation of diffusion rates in our model in the $600-800^{\circ} \mathrm{C}$ range and therefore an overestimation of $E_{a}$ and/or $D_{0}$ for this range. Although for such temperature the cumulated He release are low and therefore associated with a greater measurement error, this discrepancy more likely points out that the diffusion rate below $800^{\circ} \mathrm{C}$ does not follow the Arrhenius trend evidenced in the $800-1100^{\circ} \mathrm{C}$ range (Figure 6), as it can be inferred from the work of Motte et al. ${ }^{8,9}$ (see Table 1, lower $\mathrm{E}_{\mathrm{a}}$ and $\mathrm{D}_{0}$ values determined on basis on experiments in the $600-800^{\circ} \mathrm{C}$ range).

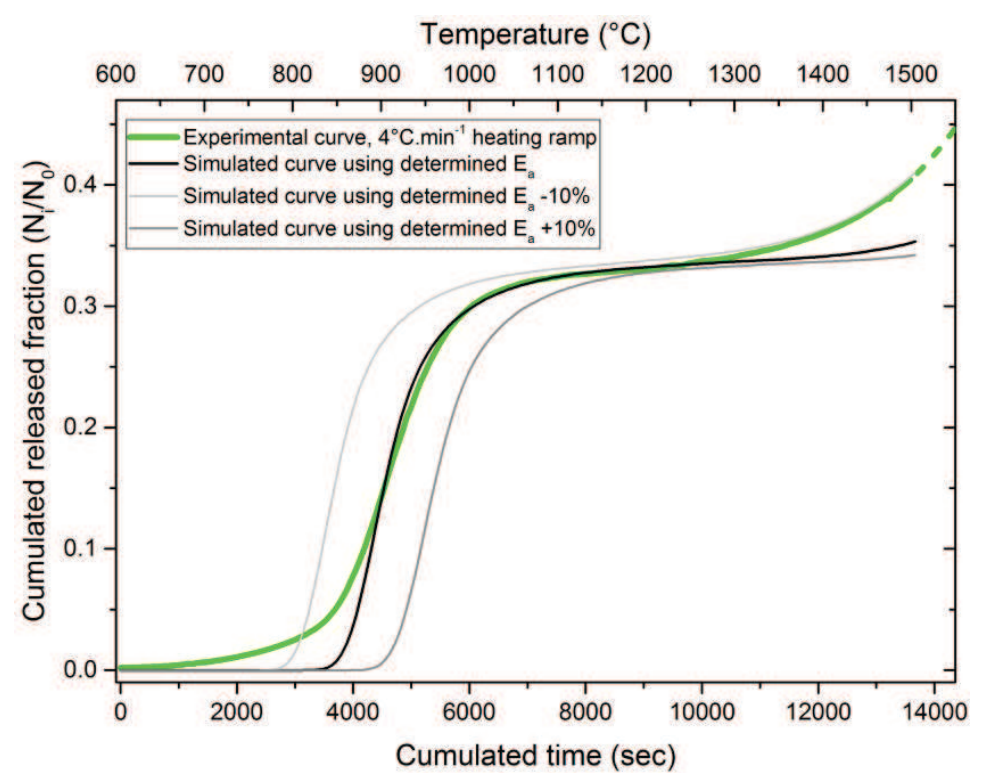

Figure 5. Experimental (green thick curve) and simulated (grey shades) release curves for the $1 \times 10^{+15}$ sample, $4^{\circ} \mathrm{C} \cdot \mathrm{min}^{-1}$ ramp experiment.

\section{DISCUSSION}

The Arrhenius plots are reported in Figure 6 and Figure 7 which allowed determining values for the apparent activation energy $\mathrm{E}_{\mathrm{a}}$, the pre-exponential factor $\mathrm{D}_{0}$ and the frequency factors $\mathrm{A}$. The values of apparent activation energy of detrapping and frequency factors of $\mathrm{He}$ escape from $\mathrm{He}$ aggregates in $\mathrm{B}_{4} \mathrm{C}$ obtained in the present study have never been determined elsewhere. On the contrary, a few experiments ${ }^{8-13,17}$ and recent DFT calculations ${ }^{14-16}$ had studied interstitial He diffusion in $\mathrm{B}_{4} \mathrm{C}$ and have extracted $\mathrm{E}_{\mathrm{a}}$ and $\mathrm{D}_{0}$ values from the results. These are gathered in Table 1 with the values determined in this work. In the next section we present and discuss these literature data.

Literature data. Chronologically, the first study of He thermally activated release from $\mathrm{B}_{4} \mathrm{C}$ was done by Clayton et al. ${ }^{10}$ by neutron irradiating (thermalized neutrons spectrum) samples with different ${ }^{10} \mathrm{~B}$ isotopic contents then measuring He release after tens of hours successive annealing from 500 to $1000^{\circ} \mathrm{C}$. Scattered data were obtained in their Arrhenius plot but still an average $\mathrm{E}_{\mathrm{a}}$ of $1.26 \mathrm{eV}$ was determined. Looking closely to their results and integrating facts that Clayton et al. were unaware 
of at the time of their study, we undertook the elimination of some of their data points. First the existence of a low but non-negligible He release at low temperatures as observed by us and Koyrshin ${ }^{13}$ naturally warrants to remove the data point at $500^{\circ} \mathrm{C}\left(10^{-20} \mathrm{~m}^{2} \cdot \mathrm{sec}^{-1}\right.$ while values down to $10^{-23} \mathrm{~m}^{2} \cdot \mathrm{sec}^{-1}$ are to be expected), as well as that at $600^{\circ} \mathrm{C}$. Then back to 1961 Clayton et al. were also unaware of the existence of traps (bubbles first published by Copeland et al. ${ }^{45}$ in 1972). As such, when reaching their $900^{\circ} \mathrm{C}$ plateau, from tens of hours of heat treatment in the $500-850^{\circ} \mathrm{C}$ range, they probably already released from their samples the majority of interstitial He. Their diffusion coefficients at $900^{\circ} \mathrm{C}$ and over thus represent a mixture of the little remaining of interstitial $\mathrm{He}$ and of the slow release from He aggregates; naturally these can as well be discarded. With this thinning, it was possible to determine from Clayton et al. ${ }^{10} \mathrm{~B}$ "depleted" and "normal" (i.e. natural enrichment) samples $E_{a}$ values of respectively 2.1 and $3.0 \mathrm{eV}$ with far better alignment of data points in Figure 6 than in their report. Most notably the plotting of Clayton et al.'s validated data points $\left(650-850^{\circ} \mathrm{C}\right.$ range) align quite well with the present study results obtained for the $10^{+13}$ and $10^{+14}$ at.cm- samples in the $850-1250^{\circ} \mathrm{C}$ range. Furthermore, it is interesting to note that the average He molar concentration in Clayton et al.'s ${ }^{10} \mathrm{~B}$ depleted" and "normal" samples in Table 1 are calculated to be about 0.004 and 0.008 mol.\% respectively. From the TRIM calculations helium concentration in our implanted $10^{+13}$ and $10^{+14}$ at. $\mathrm{cm}^{2}$ samples are expected to reach at the peak maximum 0.0007 and $0.007 \mathrm{~mol} \%$, respectively. It therefore suggests that the He insertion method, i.e. thermal neutron irradiation vs. ion implantation, does not seem to greatly influence the diffusion of interstitial $\mathrm{He}$ in $\mathrm{B}_{4} \mathrm{C}$.

The next $\mathrm{E}_{\mathrm{a}}$ value we retrieved from literature data is that by Emel'yanov et al. ${ }^{11}$ in early 1970's. In their study, they heated $\mathrm{B}_{4} \mathrm{C}$ neutron irradiated samples $\left(7 \times 10^{+18} \mathrm{n} . \mathrm{cm}^{-2}\right.$, and $\sim 0.02 \mathrm{~mol} . \% \mathrm{He}$ in average) at different heating rates and deduced from the temperature difference of the maximum release rates an activation energy of 1.73 and $2.15 \mathrm{eV}$ for sintering temperature of 1200 and $2400^{\circ} \mathrm{C}$, respectively.

Next Hollenberg et al. ${ }^{7,12}$, Kovyrshin ${ }^{13}$ and Bespalov and Pavlinov ${ }^{17}$ also published $\mathrm{E}_{\mathrm{a}}$ values. However these works should all be discarded according to the following reasons:

- Hollenberg wrongfully assumed that 1) once a helium atom reached a grain boundary it would be released out of the material, which is never experimentally observed (on the contrary, it has been shown that helium gets trapped at the grain boundaries) and 2) that in their experimental conditions bubble traps were not quantitatively formed again in contradiction with numerous works, see Motte and reference therein ${ }^{8,8}$.

In the $700-1000^{\circ} \mathrm{C}$ temperature range Kovyrshin ${ }^{13}$ curiously obtained release profiles with two close release rates maximum and therefore obtained two $E_{a}$ values, independently of He concentration. These unusual profiles might be caused by an inhomogeneity in grain size (e.g. a bimodal distribution of grain size), however the publication is insufficiently detailed to verify this hypothesis.

Finally a work by Bespalov and Pavlinov ${ }^{17}$ reporting an experimental $\mathrm{E}_{\mathrm{a}}$ value of $1.5 \mathrm{eV}$ for $\mathrm{He}$ diffusion in $\mathrm{B}_{4} \mathrm{C}$ was cited by Kovyrshin ${ }^{13}$ but we were unable to retrieve it. With no way to assess it, it is preferable not to consider it.

More recently experimentally determined $\mathrm{E}_{\mathrm{a}}$ value for He diffusion in $\mathrm{B}_{4} \mathrm{C}$ was obtained by Motte et $\mathrm{al}^{8,9}$. It consisted in a $\mathrm{B}_{4} \mathrm{C}$ plate implanted by ${ }^{3} \mathrm{He}$ at $2 \times 10^{+15}$ at. $\mathrm{cm}^{-2}$ leading to He concentration of $\sim 0.05 \mathrm{~mol} . \%$ at the peak maximum. The $\mathrm{B}_{4} \mathrm{C}$ material comes from the same fabrication batch as the present samples, which will facilitate results comparison. The evolution of He implantation profile was monitored by Nuclear Reaction Analysis (NRA) before and after annealing treatments. From this 
evolution an $\mathrm{E}_{\mathrm{a}}$ value of $2.0 \pm 0.2 \mathrm{eV}$ was determined in the $600-800^{\circ} \mathrm{C}$ range. The determined diffusion rates are reported in Figure 6.

Finally $E_{a}$ values determined by DFT calculations were published ${ }^{14,16}$. Schneider et al. ${ }^{14}$ initially studied the stability of He interstitials, first identifying the various possible sites, then used the results to determine the most probable He migration paths and energy barriers to diffusion. They notably found that the icosahedral cages of the $\mathrm{B}_{4} \mathrm{C}$ structure are not concerned by He insertion and mobility and that the latter process is done through inter-icosahedra channels only. Schneider et al. also determined that He mobility is facilitated between $\{111\}$ planes, thus in $2 \mathrm{D}$, with a low $\mathrm{E}_{\mathrm{a}}(1.2-1.3$ $\mathrm{eV}$ ); they further suggest this characteristic to be responsible of the $\mathrm{He}$ bubble alignment and stretching toward a flat disk shape often observed along the $\{111\}$ planes. 3D diffusion is calculated to happen with a minimal $\mathrm{E}_{\mathrm{a}}$ of $2.22 \mathrm{eV}$ for stoichiometric $\mathrm{B}_{4} \mathrm{C}$ and $1.9 \mathrm{eV}$ for the isostructural boronrich $\left(\mathrm{B}_{13} \mathrm{C}_{2}\right)$ boron carbide. Shortly after, You et al. ${ }^{16}$ also employed DFT and concluded to a very close $\mathrm{E}_{\mathrm{a}}$ for He 3D diffusion $\left(2.17 \mathrm{eV}\right.$ ). Gillet et al. ${ }^{15}$ (same research team as Schneider et al.) latter supplement their study by implementing irradiation induced defects and charge effects in their simulated supercells and observed the effect on the mobility of He. They chiefly looked at the most probable defect, a vacancy of the boron atom located at the chain centres (experimentally confirmed ${ }^{46}$ ), and found that if such defect is present this will quantitatively affect He 2D diffusion between $\{111\}$ planes as the activation energy of $\mathrm{He}-\mathrm{V}_{\mathrm{o}}{ }^{\prime \prime}$ dissociation is in the range 2.1-2.6 eV, i.e. values similar as the one found for 3D diffusion ${ }^{14}$. It is worthy to remind that such defects are expected not only in irradiated boron carbide such as the herein mentioned works ${ }^{9,10,12,13}$ but also in the damage queue of the implanted He, as is the case of our work (Figure 1), in Motte et al. ${ }^{8,9}$ study, and also in undamaged boron carbide to a lesser extent ${ }^{47}$.

Discussion of He diffusion and release. The trustable values of $E_{a}$ for interstitial He diffusion in boron carbide found in literature are thus gathered in Table 1, while the associated available diffusion coefficients are reported in Figure 6 as a function of temperature, along with the present results. There is some scattering in the reported $E_{a}$ values. This is presumably due to differences in experimental approaches (DFT, He implantation and reactor irradiation) and to differences in the experimental parameters in general (He concentration, $\mathrm{B} / \mathrm{C}$ ratio, impurities, $\mathrm{B}_{4} \mathrm{C}$ microstructure, concentration of native long range defects such as twins ${ }^{48,49}$, etc.). Nonetheless, the present study has the advantage to present results where the only notable difference from one sample to another is the helium content, although it incidentally modifies the defect concentration in and near the implantation zone.

About the first main He release, from Figure 6 one can note that the interstitial diffusion rates of $\mathrm{He}$ in the $1 \times 10^{+13}$ and $1 \times 10^{+14} \mathrm{~B}_{4} \mathrm{C}$ samples are very close, while that of the $1 \times 10^{+15} \mathrm{at}_{\mathrm{cm}} \mathrm{cm}^{2}$ sample are in average 3 times faster, possibly suggesting an enhancement of interstitial He diffusion when increasing implantation defects level. All but one diffusion rates (at $800^{\circ} \mathrm{C}$ for the $1 \times 10^{+13}$ sample) align in Figure 6 allowing determining $E_{a}$ and $D_{0}$. The Arrhenius plots for the three fluences are quite similar as demonstrated by the $\mathrm{E}_{\mathrm{a}}$ values found in a narrow range, 2.6 to $3.1 \mathrm{eV}$, (Table 1 ). This fact strongly suggests that the same general diffusion process is active for the three fluences in the range $800-1050^{\circ} \mathrm{C}$. In their work by DFT, Gillet et al. ${ }^{15}$ evidenced that $\mathrm{B}_{4} \mathrm{C}$ chain vacancies, the main irradiation/implantation-induced defect, should slow down He fast-diffusion along $\{111\}$ planes, as He atom would be transiently trapped by such defect $\left(\mathrm{E}_{\mathrm{a}}\right.$ of $\mathrm{He}-\mathrm{V}_{\mathrm{o}}$ " dissociation is 2.1-2.6 eV, thus a little over $\mathrm{E}_{\mathrm{a}} 2 \mathrm{D}$ diffusion between two defect-free $\{111\}$ planes). This suggests that increasing fluence (thus increasing defects concentration) should cause a decrease in He diffusion rates and an increase of apparent $\mathrm{E}_{\mathrm{a}}$ of He diffusion. This is however not what the present study evidences (slight or no effect of fluence on He diffusion characteristics). Nevertheless this may be due to our range of 
studied fluence being insufficient to evidence this theorized influence. When comparing our results with literature data, we note a general alignment (Figure 6). The $\mathrm{E}_{\mathrm{a}}$ we determined 2.6-3.1 eV are however found at the higher end of the ones selected from literature (1.73-3.0, Table 1). Most notably the present results differ from that of Motte et al. ${ }^{8,9}$, although they worked on the same $\mathrm{B}_{4} \mathrm{C}$ material and with implanted $500 \mathrm{keV} \mathrm{He}$ as well $\left(2 \times 10^{+15}\right.$ at.cm $\left.\mathrm{cm}^{-2}\right)$. They indeed found a lower $\mathrm{E}_{\mathrm{a}}(\sim 2.0 \mathrm{eV})$ from results in the range $600-800^{\circ} \mathrm{C}$ as graphically evidenced by the lower slope of the Arrhenius plot in Figure 6. Meanwhile we note that the $800^{\circ} \mathrm{C}$ data point of the $1 \times 10^{+13}$ sample (opened symbol) diverges from our other results and we remind the fact that by using $\mathrm{E}_{\mathrm{a}}$ and $\mathrm{D}_{0}$ values determined from $800^{\circ} \mathrm{C}$ we constantly fail to reproduce correctly the TDS release curves in the $600-800^{\circ} \mathrm{C}$ range (see Figure 5 e.g., calculated release underestimating the experimental release in this temperature range). These observations hint us that a change in diffusion mechanism may occur around $800^{\circ} \mathrm{C}$. To further explore this possible break in Arrhenius plot, three new NRA experiments were performed in addition to the ones presented in Motte et al. paper ${ }^{8}$ (same $\mathrm{B}_{4} \mathrm{C}$ batch, ${ }^{3} \mathrm{He}$ fluence of $2 \times 10^{+15}$ at. $\mathrm{cm}^{-2}$, and experimental NRA procedure). The newly obtained data points, at $900^{\circ} \mathrm{C} / 211 \mathrm{sec}$ (to have a better overlapping of TDS and NRA temperature ranges) and at $600^{\circ} \mathrm{C} / 30 \mathrm{~h}$ and $700^{\circ} \mathrm{C} / 1 \mathrm{~h}$ (to confirm the absence of a drift in NRA measurements) are plotted in Figure 6 as dark-green dots. NRA experiment leads to a $D$ s value of $7.6 \times 10^{-16} \mathrm{~m}^{2} . \mathrm{s}^{-1}$ for ${ }^{3} \mathrm{He}$ in $\mathrm{B}_{4} \mathrm{C}$ at $900^{\circ} \mathrm{C}$. Correcting by a $\sqrt{3} / \sqrt{4}$ factor to account for the isotopic mass effect on diffusion kinetics, one can estimate ${ }^{4} \mathrm{He}$ isotope diffusion rate would had been $6.5 \times 10^{-16} \mathrm{~m}^{2} . \mathrm{s}^{-1}$, i.e. extremely close to the $5.0 \times 10^{-16} \mathrm{~m}^{2} . \mathrm{s}^{-1}$ value determined by TDS at the same temperature. Furthermore, as visually shown by the dotted segment in Figure 6, if taking Motte et al. $\mathrm{D}_{0}$ and $\mathrm{E}_{\mathrm{a}}$ values ${ }^{8,9}$ and assuming the continuity of their Arrhenius trend up to $900^{\circ} \mathrm{C}$, a ${ }^{3} \mathrm{He}$ diffusion rate of $3.3 \times 10^{-16} \mathrm{~m}^{2} . \mathrm{s}^{-1}$ was expected, quite far from the $7.6 \times 10^{-16} \mathrm{~m}^{2} . \mathrm{s}^{-1}$ measured value. All in all there are few reasons to suspect that He diffusion mechanism in $\mathrm{B}_{4} \mathrm{C}$ gets modified around the temperature of $800^{\circ} \mathrm{C}$. Interestingly, annealings at such temperature of neutronirradiated $\mathrm{B}_{4} \mathrm{C}$ was reported to allow the "healing" of the $\mathrm{c}$ cell parameter ${ }^{45,50,51}$. The three publications reporting such results did not put forward a hypothesis on what phenomenon caused this lattice change. However when reminding that in $\mathrm{B}_{4} \mathrm{C} 1$ ) the boron chain central vacancy is the most probable defect induced by irradiation ${ }^{15,46}$ and 2) changes in the inter-icosahedron chains will mostly distort the crystal lattice in the $c$ direction, it is presumable that the recombination of $B_{i}-V_{B}$ Frenkel pairs causes the $\mathrm{c}$ lattice parameter "healing". The change of $\mathrm{He}$ diffusion mechanism in $\mathrm{B}_{4} \mathrm{C}$, if indeed confirmed, may thus be provoked by the thermal recombination around $800^{\circ} \mathrm{C}$ of $\mathrm{B}_{\mathrm{i}}-\mathrm{V}_{\mathrm{B}}$ Frenkel pairs.

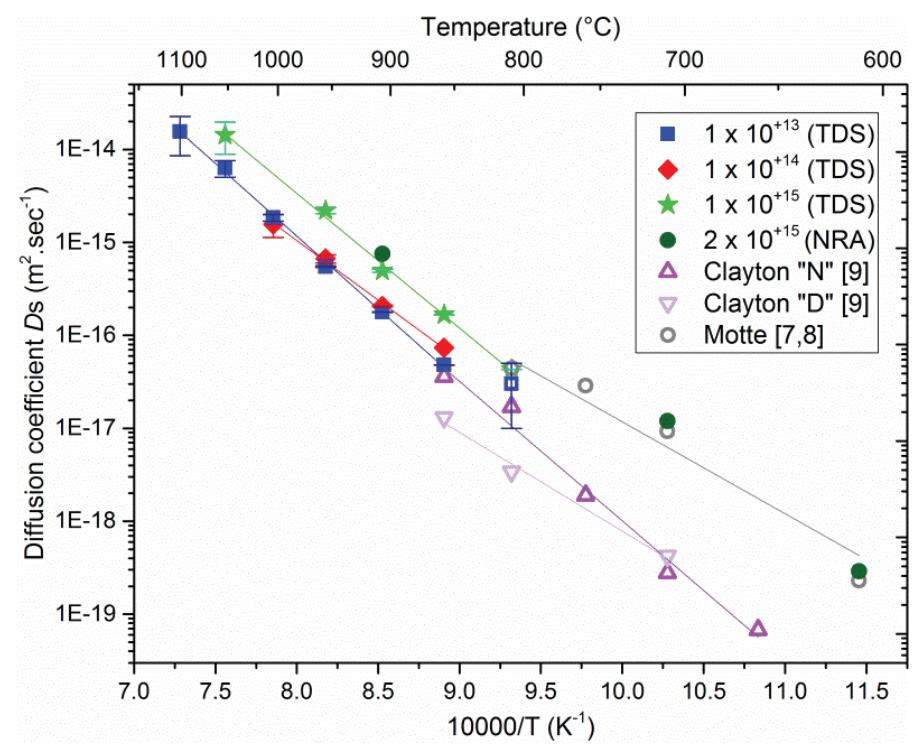


Figure 6. Diffusion coefficient of $\mathrm{He}$ in $\mathrm{B}_{4} \mathrm{C}$ as a function of the reciprocal temperature $\left(600-1100^{\circ} \mathrm{C}\right.$ range, dominated by isolated He interstitial diffusion). The straight lines correspond to Arrhenius regressions. For details about experimental conditions and data selection of the cited literature the readers are referred to Table 1 and the main text.

Table 1. List of apparent $\mathrm{E}_{\mathrm{a}}$ and $\mathrm{D}_{0}$ values for interstitial He diffusion (first release stage) determined here and obtained from literature. The general experimental conditions employed to obtain these values are also summarized. Standard error on $\mathrm{D}_{0}$ is for all results \pm 1 order of magnitude. $\mathrm{He} /(\mathrm{B}+\mathrm{C})$ is expressed as the average concentration for the neutron irradiation studies and as concentration at implantation peak maximum for the implantation studies.

\begin{tabular}{|c|c|c|c|c|c|c|c|c|c|}
\hline ref. & $\begin{array}{c}\text { nature } \\
\text { of study }\end{array}$ & $\begin{array}{c}\text { fluence } \\
\left(\text { at.cm }^{-2}\right) \\
\end{array}$ & $\begin{array}{c}\mathrm{He} /(\mathrm{B}+\mathrm{C}) \\
(\mathrm{mol} . \%)\end{array}$ & stoichio. B/C & $\% \mathrm{TD}$ & $\begin{array}{c}\text { He diffusion } \\
\mathrm{E}_{\mathrm{a}}(\mathrm{eV}) \\
\end{array}$ & $\begin{array}{c}\mathrm{D}_{0} \\
\left(\mathrm{~m}^{2} \cdot \mathrm{s}^{-1}\right) \\
\end{array}$ & $\begin{array}{c}\text { temp. } \\
\text { range }\left({ }^{\circ} \mathrm{C}\right)\end{array}$ & note \\
\hline \multirow{3}{*}{$\begin{array}{l}\text { This } \\
\text { work }\end{array}$} & \multirow{3}{*}{$\begin{array}{l}{ }^{4} \mathrm{He} \\
\text { impl. }\end{array}$} & $1 \times 10^{+13}$ & 0.0007 & \multirow{3}{*}{4.15} & \multirow{3}{*}{$>98$} & $3.13(0.24)$ & $4 \times 10^{-3}$ & $850-1100$ & \\
\hline & & $1 \times 10^{+14}$ & 0.0070 & & & $2.58(0.23)$ & $2 \times 10^{-5}$ & $850-1000$ & \\
\hline & & $1 \times 10^{+15}$ & 0.0700 & & & $2.89(0.21)$ & $1 \times 10^{-3}$ & $800-1050$ & \\
\hline \multirow{2}{*}[8,9]{} & \multirow{2}{*}{$\begin{array}{l}{ }^{3} \mathrm{He} \\
\text { impl. }\end{array}$} & \multirow{2}{*}{$2 \times 10^{+15}$} & \multirow{2}{*}{0.0500} & \multirow{2}{*}{4.15} & \multirow{2}{*}{$>98$} & $2.0(0.2)$ & $9 \times 10^{-8}$ & \multirow{2}{*}{$600-800$} & \\
\hline & & & & & & $2.2(0.2)$ & $2 \times 10^{-6}$ & & \\
\hline \multirow{2}{*}[10]{} & \multirow{2}{*}{ n irrad. } & \multirow{2}{*}{$\mathrm{n} / \mathrm{a}$} & 0.0080 & 3.77 & 98.2 & $3.0^{*}$ & $1 \times 10^{-3}$ & $650-850$ & + \\
\hline & & & 0.0040 & 3.44 & 98.5 & 2.1 & $3 \times 10^{-8}$ & $700-850$ & $T$ \\
\hline \multirow{2}{*}[11]{} & \multirow{2}{*}{$\mathrm{n}$ irrad. } & \multirow{2}{*}{$\mathrm{n} / \mathrm{a}$} & 0.0187 & \multirow{2}{*}{$?$} & \multirow{2}{*}{ ? } & 2.15 & \multirow{2}{*}{ ? } & $\sim 1000$ & \multirow{2}{*}{1} \\
\hline & & & 0.0187 & & & 1.73 & & $\sim 900$ & \\
\hline \multirow{3}{*}[14]{} & \multirow{3}{*}{ DFT } & \multirow{3}{*}{$\mathrm{n} / \mathrm{a}$} & \multirow{3}{*}{$\mathrm{n} / \mathrm{a}$} & 4 & \multirow{3}{*}{100} & 1.25 & \multirow{3}{*}{$\mathrm{n} / \mathrm{a}$} & \multirow{3}{*}{$\mathrm{n} / \mathrm{a}$} & \multirow{3}{*}{$\|$} \\
\hline & & & & 4 & & 2.20 & & & \\
\hline & & & & 6.5 & & 1.9 & & & \\
\hline [16] & DFT & $\mathrm{n} / \mathrm{a}$ & $\mathrm{n} / \mathrm{a}$ & 4 & 100 & 2.17 & $\mathrm{n} / \mathrm{a}$ & $\mathrm{n} / \mathrm{a}$ & \\
\hline$[15]$ & $\overline{\text { DFT }}$ & $\mathrm{n} / \mathrm{a}$ & $\bar{n} / \mathrm{a}$ & 4 & 100 & $\sim 2.0$ & $\overline{\mathrm{n} / \mathrm{a}}$ & $\mathrm{n} / \mathrm{a}$ & * \\
\hline \multicolumn{10}{|c|}{ 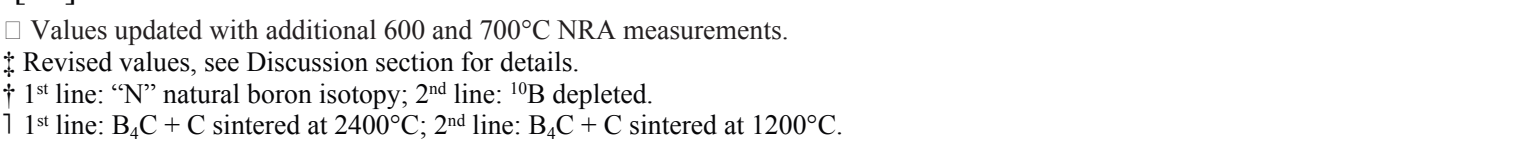 } \\
\hline $8=1$ ce & $: 2 \mathrm{D}$ diffusio & $\begin{array}{l}\text { on in-betwe } \\
\text { tween }\end{array}$ & $\{111\}$ plane & $\mathrm{d} 3^{\text {rd }}$ line & io & & & & \\
\hline
\end{tabular}

The second main He release process is now discussed. The rate constants $k_{b}$ as a function of reciprocal temperature for our 3 samples are reported in Figure 7, while Table 2 compiles the determined apparent activation energies of detrapping $\mathrm{E}_{\mathrm{a}}$ and frequency factors $\mathrm{A}$. From $k_{b}$ values in Figure 7 a change in behaviour around $1500^{\circ} \mathrm{C}$ can be observed. Below this temperature, the $1 \times 10^{+14}$ and $1 \times 10^{+13}$ samples behave very similarly with determined $E_{a}$ values close of $\sim 4 \mathrm{eV}$ and A values of $5 \times 10^{+7}$ and $1 \times 10^{+9} \mathrm{sec}^{-1}$ respectively. In the meantime during the plateaux in the range 1300$1500^{\circ} \mathrm{C}$, He release from the $1 \times 10^{+15}$ sample was realized at a slower rate $(\sim$ ten times slower than the $1 \times 10^{+14}$ sample), despite an $E_{a}$ of $2.45 \pm 0.06 \mathrm{eV}$, i.e. lower than that determined for He interstitial diffusion in the same sample. The frequency factor is thus evidently the cause of this slow release, being five to seven orders of magnitude lower than the less implanted samples (Table 2). At $1500^{\circ} \mathrm{C}$ the $1 \times 10^{+13}$ sample released its remaining $\mathrm{He}$, as it was later confirmed by further heating for 30 minutes at $1650^{\circ} \mathrm{C}$ with a measurement below detection limit hence less than $0.1 \%$ release. For the $1 \mathrm{x}$ $10^{+14}$ sample however, about $17 \%$ of the initially implanted He was still present in the material after the $1500^{\circ} \mathrm{C}$ plateau. From the experiments by samplings at 1550,1650 and $1800^{\circ} \mathrm{C}, \sim 3 \%$ of the total dose of the $1 \times 10^{+14}$ sample was released during each plateau leading to the rate constants reported in 
Figure 7. These rate constants are peculiarly all lower than that determined at $1500^{\circ} \mathrm{C}$. Moreover these three data points seem to align with the Arrhenius plot of the $1 \times 10^{+15}$ sample in the $1300-1550^{\circ} \mathrm{C}$ range. Finally in Figure 7, it can be noticed that the rate constants of the $1 \times 10^{+15}$ sample increases exponentially in the $1550-1750^{\circ} \mathrm{C}$, although the ordinate is already displayed in log scale. This is of course presumably due to $\mathrm{B}_{4} \mathrm{C}$ surface erosion by sublimation (discussed earlier) which is expected to quantitatively impair the experiments in this temperature range. To explain the whole set of data presented in Figure 7, the following hypotheses are argued:

- Release of trapped He appears to be measured active above $1200^{\circ} \mathrm{C}$. Incidentally, this temperature is also reported to correspond to the activation of changes in bubble morphology: most notably the platelets located in the implanted zone grow along the ' $c$ ' axis and (in small grain size materials) some bubbles appear in the grain boundaries not directly seeing the implanted zone, this meaning helium release from the bubbles possibly associated to vacancy mobility ${ }^{19}$. In the meanwhile, it is observed the release of mechanical constraints that are to be related to the activation of defects mobility ${ }^{50}$. It is thus possible that the release of $\mathrm{He}$ from bubbles and/or defect aggregates are made possible thanks to the activation of these aforementioned phenomena.

In the $1 \times 10^{+13}$ and $1 \times 10^{+14}$ samples for the temperature range $1250-1500^{\circ} \mathrm{C}$, the low implanted dose is sufficient to lead to the nucleation in the implantation zone of nanometric $\mathrm{He}$ accumulation centres, i.e. defect aggregates trapping He, during implantation and/or during the thermal treatments below $1250^{\circ} \mathrm{C}^{8,9}$. These $\mathrm{He}$ are efficiently trapped up to $1200^{\circ} \mathrm{C}$ as evidenced by the quantitatively low He release measured around $1150^{\circ} \mathrm{C}$ presented in Figure 2 and Figure 3 for all the samples. Such trapping of $\mathrm{He}$ is as expected proportionally greater in the $1 \times 10^{+14}$ than in the $1 \times 10^{+13}$ sample ( $\sim 22.5 \%$ vs. $24 \%$ of the implanted dose, respectively). These defect aggregates are of reduced size (not visible by $\mathrm{TEM}^{19}$ ) as compared to that discussed thereafter. Therefore an helium trapped in it will have more "chances" per unit of time to exit its aggregate thus explaining the comparatively high frequency factors A determined for the $1 \times 10^{+14}$ and $1 \times 10^{+13}$ sample in the range $1250-1500^{\circ} \mathrm{C}$ (Table 2).

- For the $1 \times 10^{+15}$ sample, still only considering the temperature range $1250-1500^{\circ} \mathrm{C}$, there are proportionally more He trapped ( $62.5 \%$, Figure 2$)$. The $1 \times 10^{+15}$ sample however differs from the other samples in the sense that for such fluence and temperatures, it is expected to host a great part of trapped $\mathrm{He}$ in nanometric up to micrometric bubbles in the implantation damaged zones (and possibly at grain boundaries if any as well). ${ }^{9,19}$ As a consequence, at a given instant proportionally less helium atoms are present at the $\mathrm{B}_{4} \mathrm{C} / \mathrm{He}$ bubble boundary, automatically lowering the $\mathrm{A}$ frequency factor related to the number of $\mathrm{He}$ escape attempts per unit of time. A second phenomenon that should influence the frequency factor $\mathrm{A}$ is the greater probability in high fluence samples for an $\mathrm{He}$ atom that just exited a trap to be retrapped in a neighbour trap since the traps volume fraction in and near the implantation zone is expected to remain proportional to the fluence. As a summary, although the comparatively lower $E_{a}$ values suggest it is energetically easier for a He atom to exit the trapping sites (i.e. He bubbles) of a highly implanted sample, experimentally the actual release rate constants of $\mathrm{He}$ are lower due to lower frequency factors.

Finally to explain why the $k_{b}$ values of the $1 \times 10^{+14}$ sample suddenly drops between 1500 and $1550^{\circ} \mathrm{C}$, it can be assumed that below $1550^{\circ} \mathrm{C}$ a part of the nanometric defect aggregates which represent $\sim 17 \%$ of the initial He population will produce, possibly through migrations and merging along the implantation damage layer, nanometric bubbles. Such phenomenon has to be done over $1100^{\circ} \mathrm{C}$. Indeed from Motte reports ${ }^{8,9}$, it is reasonable to expect the absence of bubble formation for implantation fluences of the order of $10^{+14}$ at. $\mathrm{cm}^{-2}$ after a heat treatment at $1100^{\circ} \mathrm{C}$ Alternatively, a part or all of these $17 \%$ could be from He that migrated towards grain boundaries at lower temperatures and that aggregated there in the form of bubbles. After the plateau at $1500^{\circ} \mathrm{C}$, the remaining defect 
aggregates either released all of their formerly trapped $\mathrm{He}$ and/or all formed nanometric bubbles. Further He release then only comes from the produced bubbles (either intra- or intergranular), similarly to what is encountered in the $1 \times 10^{+15}$ sample and as such following the same trend of release rate as a function of temperature (Figure 7). Again from $1550^{\circ} \mathrm{C}$ the release process is presumably tainted by bubble migration and most importantly by $\mathrm{B}_{4} \mathrm{C}$ surface erosion and as a consequence it is safer not to extract $\mathrm{E}_{\mathrm{a}}$ and $\mathrm{A}$ values for the highest temperatures of our study.

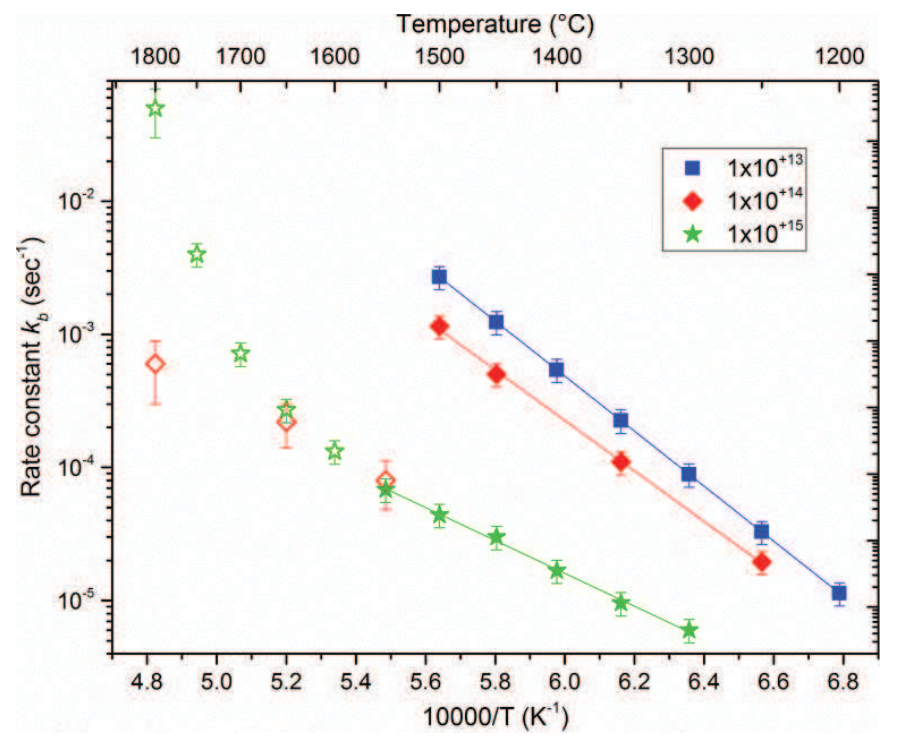

Figure 7. Rate constants $k_{b}$ as a function of the reciprocal temperature $\left(1200-1800^{\circ} \mathrm{C}\right.$ range, dominated by detrapping of He from either bubbles or defect aggregates followed by fast diffusion). From $1550^{\circ} \mathrm{C}$, erosion of the $\mathrm{B}_{4} \mathrm{C}$ surface by sublimation (and possibly trap migration) taints the results and the acquired data (hollowed symbols) are thus unexploitable for e.g. $\mathrm{E}_{\mathrm{a}}$ determination. The straight lines correspond to Arrhenius regressions.

Table 2. Apparent $\mathrm{E}_{\mathrm{a}}$ and $\mathrm{A}$ values for He detrapping as a function of sample fluences and theorized nature of the dominant trapping site. Uncertainty for A is estimated to be \pm half an order of magnitude.

\begin{tabular}{cccc}
$\begin{array}{c}\text { Fluence } \\
(\text { at.cm-2 })\end{array}$ & $\begin{array}{c}\text { Supposed nature of } \\
\text { main trapping site }\end{array}$ & $\begin{array}{c}\mathrm{E}_{\mathrm{a}} \\
(\mathrm{eV})\end{array}$ & $\begin{array}{c}\mathrm{A} \\
\left(\mathrm{s}^{-1}\right)\end{array}$ \\
\hline $1 \times 10^{+13}$ & Defect aggregates & $4.14(0.14)$ & $1 \times 10^{+9}$ \\
\hline $1 \times 10^{+14}$ & Defect aggregates & $3.79(0.19)$ & $5 \times 10^{+7}$ \\
\hline $1 \times 10^{+15}$ & Bubbles & $2.47(0.20)$ & $4 \times 10^{+2}$
\end{tabular}

\section{CONCLUSION}

Diffusion characteristics of ion-implanted $\mathrm{He}$ in $\mathrm{B}_{4} \mathrm{C}$ were investigated by TDS (and NRA) from $600^{\circ} \mathrm{C}$ up to $\mathrm{B}_{4} \mathrm{C}$ melting point. A large grains $\mathrm{B}_{4} \mathrm{C}$ material was selected in order to render grain boundaries contribution to He outward diffusion marginal and therefore only measuring intragranular He diffusion. For the selected fluences, $1 \times 10^{+13}$ to $1 \times 10^{+15} \mathrm{He} \mathrm{cm}^{-2}$ (corresponding to maximum helium concentrations at the implantation peak from $7 \cdot 10^{-4}$ to $7.10^{-2} \mathrm{~mol} \%$ ), the apparent $\mathrm{E}_{\mathrm{a}}$ of isolated (i.e. untrapped) $\mathrm{He}$ interstitial diffusion were measured in the range 2.6-3.1 eV, with no evidence here of a dose effect on this characteristic data (Table 1). Conversely, it was observed at temperatures from $1200^{\circ} \mathrm{C}$ quantitative release of $\mathrm{He}$ that were trapped during their diffusion paths at 
lower temperature. For these "trapped" $\mathrm{He}$, the release kinetics and associated apparent $\mathrm{E}_{\mathrm{a}}$ of detrapping were found to depend strongly on the nature of the accumulation centre (see Figure 7 and Table 2), i.e. defect aggregates ( $E_{a}$ of $\sim 4 \mathrm{eV}$ but high detrapping rate constants) vs. He bubbles $\left(E_{a}\right.$ of $\sim 2.5 \mathrm{eV}$ but low detrapping rate constants). With an industrial point of view, this suggests that a high, incidental temperature spike could provoke a massive release of $\mathrm{He}$. The consequences of this potential threat has thus to be further assessed, should $\mathrm{B}_{4} \mathrm{C}$ be selected as neutron absorber for GenIV reactors.

A natural continuation of this work will be to perform a similar study on $\mathrm{B}_{4} \mathrm{C}$ with smaller grains to investigate the effect of grain boundaries on $\mathrm{He}$ thermal release from $\mathrm{B}_{4} \mathrm{C}$. One may also investigate by other means ( $\mu$-Raman, TEM, etc.) He-containing $\mathrm{B}_{4} \mathrm{C}$ after different annealing treatments to confirm or infirm the herein proposed behaviors. Furthermore, inspired by studies such as that of Martin et al. ${ }^{52,53}$, it would be beneficial to investigate the co-implantation of $500 \mathrm{keV} \mathrm{He}$ ions with a $\mathrm{MeV}$ range heavy ion. The latter would increase the damage in the He implantation zone while being implanted far deeper in the material. This would greatly help to confirm (or infirm) that the defects created by ion-implantation (or other irradiation sources) are strongly influencing He diffusion in $\mathrm{B}_{4} \mathrm{C}$ and that $\mathrm{He}$ is not only trapped or slowed down in He bubbles but also in punctual structural defects.

\section{AKNOWLEDGEMENTS}

This work was partially financially supported and done in the frame of the CEA-CNRS NEEDS collaborative contract (MATABS project). Funding of the new laser heating setup was done mainly thanks to the Bordeaux university IDEX grant "Chaire d'Installation" awarded to D.H. We are highly indebted to Gaëlle Guttierez and the Jannus-Saclay team who performed the implantations.

[1] D. Gosset, Neutron absorber materials, in: D. G. Cacuci (Ed.), Handbook of Nuclear Engineering, Springer, New-York, 2010, pp. 2499-2509. ISBN 9780387981307.

[2] D. Gosset, J. M. Escleine, A. Michaux, Neutron absorber materials in fast reactors: behavior under irradiation and perspectives, proceeding of Fast Reactors and Related Fuel Cycles: Safe Technologies and Sustainable Scenarios Conference (FR13), 2013.

[3] D. Gosset, Absorber materials for Generation IV reactors, in: P. Yvon (Ed.), Structural Materials for Generation IV Nuclear Reactors, 1st Ed., Woodhead Publishing, 2017, pp 533-567. ISBN 9780081009123,

[4] G. W. Hollenberg, B. Mastel, J. A. Basmajian, Effect of irradiation temperature on the growth of helium bubbles in boron carbide, J. Am. Ceram.Soc. 63 (1979) 376-380. https://doi.org/10.1111/j.1151-2916.1980.tb10195.x

[5] T. Stoto, N. Housseau, L. Zuppiroli, and B. Kryger, Swelling and microcracking of boron carbide subjected to fast neutron irradiations, J. Appl. Phys. 68 (1990) 3198-3206. https://doi.org/10.1063/1.346370

[6] A. Jostsons, C. K. H. Dubose, Microstructure of boron carbide after fast neutron irradiation, J. Nucl. Mater., 44, no. 1, pp. 91-95, Jul. 1972.

[7] G. W. Hollenberg, J. L. Jackson, J. A. Basmajian In-reactor measurement of neutron absorber performance, Nuclear Technology, 49 (1980) 92-101. https://doi.org/10.13182/NT80-A32510 
[8] V. Motte, D. Gosset, T. Sauvage, H. Lecoq, N. Moncoffre, Helium apparent diffusion coefficient and trapping mechanisms in implanted $\mathrm{B}_{4} \mathrm{C}$ boron carbide, J. Nucl. Mater. 517 (2019) 165-174. https://doi.org/10.1016/j.jnucmat.2019.02.012

[9] V. Motte, Comportement de l'hélium implanté dans le carbure de bore $\mathrm{B}_{4} \mathrm{C}, \mathrm{PhD}$ Thesis [in French], 2017.

[10] J.C. Clayton, W.A. Bostrom, F.C. Schrag, The release of helium from slightly irradiated boron carbide and boron carbide-silicon carbide plates, WAPD-255 report, 1962.

[11] I.Y. Emel'yanov, R.V. Grebennikov, D.N. Moiseev, V.S. Karasev, V.S. Kislik, Y.F. Shved, Y.P. Mel'nik-Kutsyn, N.M. Lutsenko, P.I. Demidov, N.G. Sumets, Evolution of helium from irradiated boron-containing materials with a graphite carbon base, Soviet Atom. Energ. 31 (1971) 944-948. https://doi.org/10.1007/BF01375755

[12] G.W. Hollenberg, Helium diffusion in irradiated boron carbide, Symposium on nucleation and crystallization in glasses, Washington, HEDL-SA-2236-FP, 1981.

[13] V. G. Kovyrshin, Liberation of helium in the heating of irradiated boron carbide, Soviet Atom. Energ. 53 (1982) 570-571. https://doi.org/10.1007/BF01122102

[14] A. Schneider, G. Roma, J.-P. Crocombette, D. Gosset, V. Motte, Stability and kinetics of helium interstitials in boron carbide from first principles, J. Nucl. Mater. 496 (2017) 157-162. https://doi.org/10.1016/j.jnucmat.2017.09.020

[15] K. Gillet, G. Roma, J.-P. Crocombette, D. Gosset, The influence of irradiation induced vacancies on the mobility of helium in boron carbide, J. Nucl. Mater. 512 (2018) 288-296. https://doi.org/10.1016/j.jnucmat.2018.10.020

[16] Y. You, K. Yoshida, T. Yano, First-principles investigation of neutron-irradiation-induced point defects in $\mathrm{B}_{4} \mathrm{C}$, a neutron absorber for sodium-cooled fast nuclear reactors, Jap. J. Appl. Phys. 57 (2018) 055801. https://doi.org/10.7567/JJAP.57.055801

[17] A.G. Bespalov, L. V. Pavlinov, State and prospects of studies on the design of atomic power plants with fast neutron reactors [in Russian], 2 (1975) 696.

[18] R. Matschat, A. Dette, S. Richter, S. Recknagel, P. Barth, Certification of a boron carbide powder reference material for chemical analysis, J. Am. Ceram. Soc. 94 (2011) 4009-4016. https://doi.org/10.1111/j.1551-2916.2011.04657.x

[19] V. Motte, D. Gosset, G. Gutierrez, S. Doriot, N. Moncoffre, Helium cluster nucleation and growth in implanted $\mathrm{B}_{4} \mathrm{C}$ boron carbide, J. Nucl. Mater. 514 (2019) 334-347. https://doi.org/10.1016/j.jnucmat.2018.12.012

[20] S. Pellegrino P. Trocellier, S. Miro, Y. Serruys, É. Bordas, H. Martin, N. Chaâbane, S. Vaubaillon, J.P. Gallien, and L. Beck, The JANNUS Saclay facility: A new platform for materials irradiation, implantation and ion beam analysis, Nucl. Instrum. Methods Phys. Res. Sect. B, 273 (2012) 213-217. https://doi.org/10.1016/j.nimb.2011.07.078

[21] D. Gosset, S. Miro, S. Doriot, N. Moncoffre, Amorphisation of boron carbide under slow heavy ion irradiation, J. Nucl. Mater. 476 (2016) 198-204

[22] J.F. Ziegler, J.P. Biersack, U. Littmark, The stopping power and range of ions in solids, Pergamon, New-York, 1985. www.srim.org. 
[23] F. Linez, E. Gilabert, A. Debelle, P. Desgardin, M.-F. Barthe, Helium interaction with vacancytype defects created in silicon carbide single crystal, J. Nucl. Mater. 436 (2013) 150-157. https://doi.org/10.1016/j.jnucmat.2013.01.288.

[24] A. Özgümüs, E. Gilabert, N. Dacheux, C. Tamain, B. Lavielle, Study of radiogenic helium diffusion in the $\beta$-thorium phosphate diphosphate ceramic, J. Nucl. Mater. 373 (2008) 112-118. https://doi.org/10.1016/j.jnucmat.2007.05.038

[25] B. Lavielle, B. Thomas, E. Gilabert, G. Canchel, D. Horlait, S. Topin, F. Pointurier, C. Moulin, Development toward a double focusing isotopic separator for noble gas isotope enrichment, J. Mass Spectrom. 51 (2016) 718-723. https://doi.org/10.1002/jms.3800

[26] E. Gilabert, B. Lavielle, B. Thomas, S. Topin, F. Pointurier, C. Moulin, Ultratrace analysis of krypton isotopes by resonant ionization spectroscopy-time of flight mass spectrometry (RISTOF), J. Anal. At. Spectrom. 31 (2016) 994-1001. https://doi.org/10.1039/c5ja00423c

[27] Z. Talip, T. Wiss, E.-A. Maugeri, J.-Y. Colle, P.-E. Raison, E. Gilabert, M. Ernstberger, D. Staicu, R.J.M. Konings, Helium behaviour in stoichiometric and hyper-stoichiometric UO2, J. Eur. Ceram. Soc. 34 (2014) 1265-1277. https://doi.org/10.1016/j.jeurceramsoc.2013.11.032

[28] C. Viaud, S. Maillard, G. Carlot,C. Valot ,E. Gilabert, T. Sauvage, C. Peaucelle, N. Moncoffre, Behaviour of helium after implantation in molybdenum, J. Nucl. Mater. 385 (2009) 294-298. https://doi.org/10.1016/j.jnucmat.2008.12.005

[29] P. Garcia, E. Gilabert, G. Martin, G. Carlot, C. Sabathier, T. Sauvage, P. Desgardin, M.-F. Barthe, Helium behavior in UO2 through low fluence ion implantation studies, Nucl. Instrum. Methods B, 327 (2014) 113-116. https://doi.org/10.1016/j.nimb.2013.11.042

[30] T.Y. Kosolapova, Handbook of high temperature compounds: properties, production, applications. Hemisphere Publishing Co., New York, 1990.

[31] R.E. Taylor, D.P. DeWitt, P. E. Johnson, Spectral Emissivity at High Temperatures, Annual Report for AFOSR Grant 77-3280, 1980.

[32] G.V. Samsonov, I.A. Podchernyaeva, V.S. Fomenko, Emission coefficient of high-melting compounds, Soviet Powder Metall. and Metal. Ceram., 5 (1969) 374-379.

[33] T.I. Serebryakova, Y.B. Paderno, G.V. Samsonov, Emission Coefficients of Some Powdered High-Melting Compounds, Opt. Spectry, 8 (1960) 212-213.

[34] R.J Hayes, Determination of the emissivity of materials, NASA-CR-50487, PWA-2163, Technical Report, 1963.

[35] Z. Talip, T. Wiss, V. Di Marcello, A. Janssen, J.Y. Colle, P. Van Uffelen, P. Raison, R.J.M. Konings, Thermal diffusion of helium in ${ }^{238} \mathrm{Pu}$-doped $\mathrm{UO}_{2}$, J. Nucl. Mater., 445 (2014) 117-127. https://doi.org/10.1016/j.jnucmat.2013.10.066

[36] P. Van Uffelen, G. Pastore, V. Di Marcello, L. Luzzi, Multiscale modelling for the fission gas behaviour in the TRANSURANUS code, Nucl. Eng. Tech., 43 (2011) 477-488. https://doi.org/10.5516/NET.2011.43.6.477

[37] M. Speight, A calculation on the migration of fission gas in material exhibiting precipitation and re-solution of gas atoms under irradiation, Nucl. Sci. Eng., 37 (1969) 180-185. https://doi.org/10.13182/NSE69-A20676 
[38] P. Lösönen, On the behaviour of intragranular fission gas in $\mathrm{UO}_{2}$ fuel, J. Nucl. Mater., 280 (2000) 56-72. https://doi.org/10.1016/S0022-3115(00)00028-3

[39] R. Cornell, M. Speight, B. Masters, The role of bubbles in fission gas release from uranium dioxide, J. Nucl. Mater., 30 (1969) 170-178. https://doi.org/10.1016/0022-3115(69)90178-0

[40] H. E. Robson, P. W. Gilles, The High Temperature Vaporization Properties of Boron Carbide and the Heat of Sublimation of Boron, J. Phys. Chem., 68 (1964) 983-989. https://doi.org/10.1021/j100787a001

[41] Vapor Pressure Calculator by the Institut fur Angewandte Physik der Technishen Universität Wien. https://www.iap.tuwien.ac.at/www/surface/vapor pressure Selecting $\mathrm{Pt}$ as a substance incidentially gives vapour pressures as a function of temperature very close to that of $\mathrm{B}_{4} \mathrm{C}$, allowing to estimate the erosion rate.

[42] J. A. Sue, H. H. Troue, Effect of crystallographic orientation on erosion characteristics of arc evaporation titanium nitride coating, Surf. Coat. Tech., 33 (1987) 169-181. https://doi.org/10.1016/0257-8972(87)90186-1

[43] B. Goldstein, D. J. Szostak, V. S. Ban, Langmuir evaporation from the (100), (111A), and (111B) faces of GaAs, Surf. Sci., 57 (1976) 733-740. https://doi.org/10.1016/0039-6028(76)90358-7

[44] V. P. Tarasikov, Electron-microscopic investigation of boron carbide irradiated in a fast reactor, Atom. Energy, 106 (2009) 220-224. https://doi.org/10.1007/s10512-009-9155-9

[45] G.L. Copeland, R. G. Donnelly, W.R. Martin, Irradiation behavior of boron carbide, Nucl. Tech., 16 (1972) 226-237. https://doi.org/10.13182/NT72-A31189

[46] C.W. Tucker, P. Senio, X-ray scattering, by neutron-irradiated single crystals of boron carbide. I, Acta Cryst. 8 (1955) 371-378. https://doi.org/10.1107/S0365110X55001266

[47] R. Schmechel, H. Werheit, Structural defects of some icosahedral boron-rich solids and their correlation with the electronic properties, J. Solid State Chem. 154 (2000) 61-67. https://doi.org/10.1006/jssc.2000.881

[48] C. Cheng, K.M. Reddy, A. Hirata, T. Fujita, M. Chen, Structure and mechanical properties of boron-rich boron carbides, J. Eur. Ceram. Soc. 37 (2017) 4514-4523. https://doi.org/10.1016/j.jeurceramsoc.2017.06.017

[49] X. Yang, W.A. Goddard III, Q. An, Asymmetric twins in boron rich boron carbide, Phys. Chem. Chem. Phys. 20 (2018) 13340-13347. https://doi.org/10.1039/C8CP01429A

[50] D. Gosset, B. Kryger, J.P. Bonal, C. Verdeau, K. Froment, Evolution of thermo-physical properties and annealing of fast neutron irradiated boron carbide, J. Nucl. Mater. 500 (2018) 166175. https://doi.org/10.1016/j.jnucmat.2017.11.027

[51] H. Suzuki, T. Maruyama, T. Wakasa, Postirradiation annealing of boron carbide pellet irradiated in fast breeder reactor, J. Nucl. Sci. Tech., 16 (1979) 588-595. https://doi.org/10.1080/18811248.1979.9730950

[52] G. Martin, P. Garcia, H. Labrim, T. Sauvage, G. Carlot, P. Desgardin, M.F. Barthe, J.P. Piron, A NRA study of temperature and heavy ion irradiation effects on helium migration in sintered uranium dioxide, J. Nucl. Mater. 357 (2006) 198-205.

https://doi.org/10.1016/j.jnucmat.2006.06.021 
[53] G. Martin, C. Sabathier, G. Carlot, P. Desgardin, C. Raepsaet, T. Sauvage, H. Khodja, P. Garcia, Irradiation damage effects on helium migration in sintered uranium dioxide, Nucl. Instrum. Methods Phys. Res. Sect. B., 273 (2012) 122-126. https://doi.org/10.1016/j.nimb.2011.07.055 